Cochrane Database of Systematic Reviews

\title{
Repositioning for pressure ulcer prevention in adults (Review)
}

Gillespie BM, Chaboyer WP, McInnes E, Kent B, Whitty JA, Thalib L

Gillespie BM, Chaboyer WP, McInnes E, Kent B, Whitty JA, Thalib L.

Repositioning for pressure ulcer prevention in adults.

Cochrane Database of Systematic Reviews 2014, Issue 4. Art. No.: CD009958.

DOI: 10.1002/14651858.CD009958.pub2.

www.cochranelibrary.com 
TABLE OF CONTENTS

HEADER 1

ABSTRACT

PLAIN LANGUAGE SUMMARY

BACKGROUND

OBJECTIVES

METHODS

RESULTS

Figure 1.

Figure 2.

Figure 3.

Figure 4.

DISCUSSION

AUTHORS' CONCLUSIONS

ACKNOWLEDGEMENTS

REFERENCES

CHARACTERISTICS OF STUDIES

DATA AND ANALYSES

Analysis 1.1. Comparison $12 \mathrm{~h}$ versus $3 \mathrm{~h}$ repositioning on standard hospital mattresses, Outcome 1 Pressure ulcer risk (category 1 to 4).

Analysis 1.2. Comparison $12 \mathrm{~h}$ versus $3 \mathrm{~h}$ repositioning on standard hospital mattresses, Outcome 2 Pressure ulcer risk (category 2 to 4 ).

Analysis 2.1. Comparison $24 \mathrm{~h}$ versus $6 \mathrm{~h}$ repositioning on viscoelastic foam mattresses, Outcome 1 Pressure ulcer risk (category 1 to 4).

Analysis 2.2. Comparison $24 \mathrm{~h}$ versus $6 \mathrm{~h}$ repositioning on viscoelastic foam mattresses, Outcome 2 Pressure ulcer risk (category 2 to 4).

Analysis 3.1. Comparison 330o tilt 3-hourly overnight versus 900 tilt overnight, Outcome 1 Pressure ulcer risk (category 1 to 4). APPENDICES

WHAT'S NEW

CONTRIBUTIONS OF AUTHORS

DECLARATIONS OF INTEREST

SOURCES OF SUPPORT

DIFFERENCES BETWEEN PROTOCOL AND REVIEW

INDEX TERMS 
[Intervention Review]

\section{Repositioning for pressure ulcer prevention in adults}

Brigid M Gillespie ${ }^{1}$, Wendy P Chaboyer ${ }^{1}$, Elizabeth Mclnnes² ${ }^{2}$ Bridie Kent ${ }^{3}$, Jennifer A Whitty ${ }^{4}$, Lukman Thalib 5

1NHMRC Centre of Research Excellence in Nursing, Centre for Health Practice Innovation, Menzies Health Institute Queensland, Griffith University, Brisbane, Australia. ${ }^{2}$ Nursing Research Institute, St Vincent's Health Australia (Sydney) and Australian Catholic University (ACU), School of Nursing, Midwifery and Paramedicine, Australian Catholic University, Darlinghurst, Australia. ${ }^{3}$ School of Nursing and Midwifery, Deakin Centre for Quality and Risk Management, Deakin University, Melbourne, Burwood, Australia. ${ }^{4}$ School of Pharmacy, The University of Queensland, Brisbane, Australia. ${ }^{5}$ Department of Community Medicine, Kuwait University, Safat, Kuwait

Contact address: Wendy P Chaboyer, NHMRC Centre of Research Excellence in Nursing, Centre for Health Practice Innovation, Menzies Health Institute Queensland, Griffith University, Brisbane, Queensland, Australia.w.chaboyer@griffith.edu.au.

Editorial group: Cochrane Wounds Group

Publication status and date: Edited (no change to conclusions), published in Issue 2, 2015.

Citation: Gillespie BM, Chaboyer WP, McInnes E, Kent B, Whitty JA, Thalib L. Repositioning for pressure ulcer prevention in adults. Cochrane Database of Systematic Reviews 2014, Issue 4. Art. No.: CD009958. DOI: 10.1002/14651858.CD009958.pub2.

Copyright $@ 2015$ The Cochrane Collaboration. Published by John Wiley \& Sons, Ltd.

\section{A B S T R A C T}

\section{Background}

A pressure ulcer (PU), also referred to as a 'pressure injury', 'pressure sore', or 'bedsore' is defined as an area of localised tissue damage that is caused by unrelieved pressure, friction or shearing forces on any part of the body. PUs commonly occur in patients who are elderly and less mobile, and carry significant human and economic impacts. Immobility and physical inactivity are considered to be major risk factors for PU development and the manual repositioning of patients in hospital or long-term care is a common pressure ulcer prevention strategy.

\section{Objectives}

The objectives of this review were to:

1) assess the effects of repositioning on the prevention of PUs in adults, regardless of risk or in-patient setting;

2) ascertain the most effective repositioning schedules for preventing PUs in adults; and

3) ascertain the incremental resource consequences and costs associated with implementing different repositioning regimens compared with alternate schedules or standard practice.

\section{Search methods}

We searched the following electronic databases to identify reports of the relevant randomised controlled trials: the Cochrane Wounds Group Specialised Register (searched 06 September 2013), the Cochrane Central Register of Controlled Trials (CENTRAL) (2013, Issue 8); Ovid MEDLINE (1948 to August, Week 4, 2013); Ovid EMBASE (1974 to 2013, Week 35); EBESCO CINAHL (1982 to 30 August 2013); and the reference sections of studies that were included in the review.

\section{Selection criteria}

Randomised controlled trials (RCTs), published or unpublished, that assessed the effects of any repositioning schedule or different patient positions and measured PU incidence in adults in any setting.

\section{Data collection and analysis}

Two review authors independently performed study selection, risk of bias assessment and data extraction. 


\section{Main results}

We included three RCTs and one economic study representing a total of 502 randomised participants from acute and long-term care settings. Two trials compared the $30^{\circ}$ and $90^{\circ}$ tilt positions using similar repositioning frequencies (there was a small difference in frequency of overnight repositioning in the $90^{\circ}$ tilt groups between the trials). The third RCT compared alternative repositioning frequencies.

All three studies reported the proportion of patients developing PU of any grade, stage or category. None of the trials reported on pain, or quality of life, and only one reported on cost. All three trials were at high risk of bias.

The two trials of $30^{\circ}$ tilt vs. $90^{\circ}$ were pooled using a random effects model $\left(I^{2}=69 \%\right)$ ( 252 participants). The risk ratio for developing a PU in the $30^{\circ}$ tilt and the standard $90^{\circ}$ position was very imprecise (pooled $\mathrm{RR} 0.62,95 \% \mathrm{Cl} 0.10$ to $3.97, \mathrm{P}=0.62$, very low quality evidence). This comparison is underpowered and at risk of a Type 2 error (only 21 events).

In the third study, a cluster randomised trial, participants were randomised between 2-hourly and 3-hourly repositioning on standard hospital mattresses and 4 hourly and 6 hourly repositioning on viscoelastic foam mattresses. This study was also underpowered and at high risk of bias. The risk ratio for pressure ulcers (any category) with 2-hourly repositioning compared with 3-hourly repositioning on a standard mattress was imprecise (RR $0.90,95 \% \mathrm{Cl} 0.69$ to 1.16 , very low quality evidence). The risk ratio for pressure ulcers (any category) was compatible with a large reduction and no difference between 4-hourly repositioning and 6-hourly repositioning on viscoelastic foam ( $R R 0.73,95 \% \mathrm{Cl} 0.53$ to 1.02 , very low quality evidence).

A cost-effectiveness analysis based on data derived from one of the included parallel RCTs compared 3-hourly repositioning using the $30^{\circ}$ tilt overnight with standard care consisting of 6-hourly repositioning using the $90^{\circ}$ lateral rotation overnight. In this evaluation the only included cost was nursing time. The intervention was reported to be cost saving compared with standard care (nurse time cost per patient $€ 206.6$ vs $€ 253.1$, incremental difference $€-46.5 ; 95 \% \mathrm{Cl}: €-1.25$ to $€-74.60)$.

\section{Authors' conclusions}

Repositioning is an integral component of pressure ulcer prevention and treatment; it has a sound theoretical rationale, and is widely recommended and used in practice. The lack of robust evaluations of repositioning frequency and position for pressure ulcer prevention mean that great uncertainty remains but it does not mean these interventions are ineffective since all comparisons are grossly underpowered. Current evidence is small in volume and at risk of bias and there is currently no strong evidence of a reduction in pressure ulcers with the $30^{\circ}$ tilt compared with the standard $90^{\circ}$ position or good evidence of an effect of repositioning frequency. There is a clear need for highquality, adequately-powered trials to assess the effects of position and optimal frequency of repositioning on pressure ulcer incidence.

The limited data derived from one economic evaluation means it remains unclear whether repositioning every 3 hours using the $30^{\circ}$ tilt is less costly in terms of nursing time and more effective than standard care involving repositioning every 6 hours using a $90^{\circ}$ tilt.

\section{PLAIN LANGUAGE SUMMARY}

\section{Repositioning to prevent pressure ulcers}

Pressure ulcers, also called pressure injury, pressure sores, decubitus ulcers and bed sores are caused by pressure, rubbing or friction at the weight-bearing bony points of the body (such as hips, heels and elbows). A pressure ulcer is characterised by an area of localised injury to the skin or underlying tissue over a bony prominence that results from pressure or shearing, or a combination of both. Pressure ulcers most commonly occur in the elderly, or those who are immobile, either when in bed or sitting. Repositioning (i.e. turning) is one strategy used alongside other preventative strategies to relieve pressure, and so prevent development of pressure ulcers. Repositioning involves moving the person into a different position to remove or redistribute pressure from a particular part of the body.

We identified three studies which recruited 502 people. Evidence to support the use of repositioning to prevent pressure ulcers is low in volume and quality and we still do not know if particular positions or frequencies of repositioning reduce pressure ulcer development. None of the trials reported on pain or quality of life. There is a need for further research to measure the effects of repositioning on pressure ulcer development and to find the best repositioning regimen in terms of frequency and position. It is important to emphasise that this lack of evidence showing that repositioning is effective or which repositioning regimen is the best does not mean that repositioning is ineffective. 


\section{B A C K G R O U N D}

\section{Description of the condition}

A pressure ulcer (PU) (also known as pressure sore, pressure injury, or bedsore) is "a localised injury to skin or underlying tissue usually over a bony prominence as a result of pressure or pressure in combination with shear" (European Pressure Ulcer Advisory Panel 2009; NPUAP 2009). PUs occur when the soft tissue is compressed between a bony prominence and an external surface for a prolonged period of time.

PU classification systems provide an accurate and consistent means by which the severity and level of tissue injury of a PU can be described and documented (Australian Wound Management Association 2011).The words 'stage' (European Pressure Ulcer Advisory Panel 2009), 'grade', and 'category' are used interchangeably to describe the levels of soft-tissue injury. The original staging system includes Stages 1 to 4. Stage 1 reflects persistent non-blanching erythema (redness) of the skin (Australian Wound Management Association 2011; European Pressure Ulcer Advisory Panel 2009). Stage 2 involves partial-thickness skin loss (epidermis and dermis). Stage 3 reflects full-thickness skin loss involving damage, or necrosis, of subcutaneous tissue, whereas in Stage 4 the damage extends to the underlying bone, tendon or joint capsule. However, more recently, two additional classifications have been identified, namely: 'unclassified/unstageable' and 'deep tissue injury' (Australian Wound Management Association 2011; European Pressure Ulcer Advisory Panel 2009; National Pressure Ulcer Advisory Panel 2007). PUs are associated with pain, an increased risk of infection and sepsis, longer hospital stays, higher hospitalisation costs and mortality (Institute for Healthcare Improvement 2008; Thomas 1996).

Despite a general consensus that PUs are preventable (Brandeis 2001), hospital-acquired PUs are among the top five adverse events reported. Estimates of PU incidence in hospitalised patients have ranged from less than 3\% to over 30\% (Nixon 2006; Queensland Health 2008 Mulligan 2011,Schuurman 2009). Costs of treating PUs vary globally, but represent a considerable financial burden on hospital budgets wherever they occur. Costs to the Australian healthcare system have been estimated at AUD 285 million per annum (Mulligan 2011). The total cost for treatment of PUs in the UK was GBP 1.4 billion to GBP 2.1 billion annually (4\% of total National Health Service's expenditure) (Bennett 2004), whilst the total cost in the US was estimated at USD 11 billion per year (Institute for Healthcare Improvement 2008). Much of this cost is allocated to nursing time (Bennett 2004).

Immobility and physical inactivity are considered to be major risk factors for PU development in hospitalised patients (Allman 1995; Institute for Healthcare Improvement 2008; Lindgren 2004), however, the aged and individuals who have severely compromised states of health are particularly at risk (Institute for Healthcare Improvement 2008). For example, of the 3.55 million hospital admissions in Australia each year (excluding day cases), $50 \%$ of patients will be at risk of PUs and $10 \%$ or more will develop an ulcer (Queensland Health 2009). Screening tools based on individuals' levels of activity and mobility scores have been widely used for the assessment of PU risk (Braden 2005; Jalali 2005; Thompson 2005). Various interventions are in use and believed to reduce the incidence of PUs with varying levels of supporting evidence including different mattresses and overlays (Nixon 2006; Reddy 2006; Vanderwee 2005) and regular position changes (Buss 2002; Krapfl 2008; Reddy 2006).

\section{Description of the intervention}

Repositioning (i.e. turning people to change their body position to relieve or redistribute pressure) has long been a fundamental component of pressure ulcer prevention (PUP). Manual repositioning regimens are used in PU risk-prevention programs to re-distribute pressure between the body and the support surface (Manorama 2010).The $90^{\circ}$ lateral position has been shown in laboratory studies to decrease blood flow and transcutaneous oxygen tension close to anoxic levels (extremely low levels of oxygen) and to increase interface pressure. Conversely, this appears not to be the case when the patient is placed in a $30^{\circ}$ lateral inclined tilt position. Repositioning is regarded as also important for the prevention of other complications associated with prolonged immobility such as pneumonia, joint contractures, and urinary tract infections.

Best practice guidelines developed in Europe, USA and Australia advocate routine repositioning of people at risk of PUs. These guidelines commonly advocate two-hourly repositioning (Australian Wound Management Association 2011; Defloor 2000; European Pressure Ulcer Advisory Panel 1998; Queensland Health 2009). These recommendations appear to be based on small studies (not RCTs) conducted 20 or more years ago, that either compared different repositioning schedules or repositioning schedules with no manual repositioning (spontaneous body movements) (Exton-Smith 1961; Norton 1962; Palmen 1987; Smith 1990). The usefulness of these studies for today's decision making is further compromised since the standard of hospital mattresses has greatly improved since then.

\section{How the intervention might work}

Pressure, from lying or sitting on a particular part of the body results in oxygen deprivation to the particular area (Defloor 2000). Normally, this results in pain and discomfort, which stimulates the person to change position. However, if the person is unable to reposition themselves, or has impaired sensation and therefore does not experience the discomfort, assistance will be required. Repositioning reduces the duration of pressure experienced by the tissues and so decreases tissue hypoxia (Catania 2007) and consequently the theoretical risk of pressure ulceration (Braden 1987).

\section{Negative aspects of frequent repositioning}

Whilst frequent repositioning underpins current practice guidelines, it may also be associated with negative consequences for patients, nursing staff and health care (Australian Institute of Health and Welfare 2009; Bureau of Labor Statistics 2002; Carskadon 2005; Dawson 2007; Humphries 2008; Raymond 2004; Vieira 2009). Repositioning can lead to disruption of sleep, particularly sleep fragmentation (Humphries 2008). In acutely ill people, disruption of sleep can lengthen recovery, suppress immune function and predispose people to infection (Carskadon 2005; Raymond 2004). A sleep cycle, which has light and deep stages of sleep, occurs about every 90 minutes. Consequently if repositioning is undertaken every two hours, it may result in fragmentation of sleep at a detrimental stage of the sleep cycle (Dawson 2007).

Other negative effects of repositioning include possible increases in patients' pain perception. Although regular movement is important, unnecessary repositioning may cause increased discomfort for people with wounds, stiff joints, bony pain or contractures. 
In addition to people experiencing the negative effects of repositioning, nurses experience musculoskeletal disorders at a rate exceeding that of workers in construction, mining, and manufacturing (Bureau of Labor Statistics 2002). These injuries are attributed partly to repeated manual patient-handling activities, often associated with repositioning patients and working in extremely awkward positions (Bureau of Labor Statistics 2002; Vieira 2009). Back pain and injury have a major impact on the efficiency of the nursing workforce (Trinkoff 2001). Registered nurses rank seventh across all occupations for back injuries involving days away from work in private industry (Bureau of Labor Statistics 2002). Back injuries and the resultant workers' compensation claims for nurses are expensive (Dawson 2007). For example, injuries in the healthcare sector cost Australia over AUD 4.3 billion in 2005 to 2006 (Australian Safety and Compensation Council 2009). Reducing the amount of manual handling undertaken by nurses when repositioning patients could have major nursing and hospital benefits.

\section{Why it is important to do this review}

PUs may be painful, distressing and life-threatening (causing infection, sepsis and even death), yet many are preventable (Allman 1997; Schuurman 2009). Manual repositioning regimens are used in PU risk-prevention programs to alternate areas of pressure distribution between the body and the support surface, including when sitting or lying in a chair (Manorama 2010). These strategies have major implications for repositioning hospitalised patients and warrant investigation.

Whilst the potential negative aspects of repositioning have been described, the magnitude of any benefits are also uncertain, as is the optimum frequency of repositioning and the best position. It is noteworthy that, more recently, the National Pressure Ulcer Advisory Panel 2007 and the European Pressure Ulcer Advisory Panel 2009 Guidelines did not advocate 2-hourly repositioning as best practice due to a lack of empirical evidence. A rigorous systematic review is required to summarise current evidence for the effects of repositioning of adults, the optimal repositioning schedules, and to ensure that future trials are based on the best available evidence.

\section{OB JECTIVES}

The objectives of this review were to:

1. assess the effects of repositioning on the prevention of PUs in adults, regardless of risk or in-patient setting;

2. ascertain the most effective repositioning schedules for preventing PUs in adults; and

3. ascertain the incremental resource consequences and costs associated with implementing different repositioning regimens compared with alternate schedules or standard practice.

\section{METHODS}

\section{Criteria for considering studies for this review}

\section{Types of studies}

Any RCT that used a method of random allocation of adult patients (without an existing PU at baseline) between two or more alternative repositioning interventions for $\mathrm{PU}$ prevention was eligible. We also included cluster-RCTs, irrespective of the cluster group (i.e. patient, nurse, hospital). We excluded cross-over trials (even if ran- domised) and quasi-randomised studies, i.e. studies where treatment allocation was, for example, alternate or by date of birth.

The review of health economic evidence included comparative full and partial economic evaluations conducted within the framework of eligible RCTs (i.e. cost-effectiveness analyses, cost-utility analyses, cost-benefit analyses and cost-analyses of a repositioning intervention and a relevant comparator), as well as RCTs reporting more limited information, such as estimates of resource use or costs associated with repositioning and a comparator. The review considered only health economics studies conducted alongside effectiveness studies included in the effectiveness component of the review.

\section{Types of participants}

Any adult, without an existing PU, admitted to any healthcare or long-term care setting.

\section{Types of interventions}

We anticipated that likely comparisons would include repositioning regimens compared with other standard practices or with alternative repositioning regimens. We included studies evaluating the following comparisons:

1. Comparisons between the frequencies of repositioning, for example 2-hourly turning, 3-hourly turning, 4-hourly turning etc. where the only systematic difference between groups was the frequency of repositioning.

2. Comparisons between different positions for repositioning, for example chair positioning, $30^{\circ}$ recumbent tilt versus $90^{\circ}$ lateral rotation, where the only systematic difference between groups was the positioning.

3. Comparisons of the repositioning regimen with standard practice (as defined by the author(s)).

\section{Types of outcome measures}

\section{Primary outcomes}

The proportion of participants with a new PU of any stage, grade,or category using previously defined criteria (European Pressure Ulcer Advisory Panel 1998; European Pressure Ulcer Advisory Panel 2009; National Pressure Ulcer Advisory Panel 2007), or however defined by the trial authors, anywhere on the body following recruitment into the study. We excluded trials where the unit of analysis was the $\mathrm{PU}$ and not the person or group.

\section{Secondary outcomes}

1. Health-related quality of life (HRQoL) including utility scores (however reported by the author(s)).

2. Procedural pain (however reported by the author(s)).

3. Patient satisfaction (however reported by the author(s)).

4. Cost including: costs of PU prevention; costs of related health practitioner time or visits; costs avoided by PU prevention (e.g. treatment costs per patient per PU wound; costs to treat adverse events, infections or complications of PU; duration or costs of hospital stay for PU wound healing, adverse events and complications; indirect costs to society associated with PU such as lost productivity).

5. Incremental cost per event avoided, such as per additional PU prevented; incremental cost per life year gained; incremental 
cost per quality adjusted life year (QALY) gained, and cost-benefit ratio.

\section{Search methods for identification of studies}

\section{Electronic searches}

We searched the following electronic databases to identify reports of relevant RCTs:

1. The Cochrane Wounds Group Specialised Register (searched 06 September 2013);

2. The Cochrane Central Register of Controlled Trials (CENTRAL) (2013, Issue 8);

3. Ovid MEDLINE (1948 to August, Week 4, 2013);

4. Ovid MEDLINE (In-Process \& Other Non-Indexed Citations September 04, 2013);

5. Ovid EMBASE (1974 to 2013 Week 35);

6. EBSCO CINAHL (1982 to 30 August 2013).

We searched the Cochrane Central Register of Controlled Trials (CENTRAL) using the following exploded MeSH headings and keywords:

\#1 MeSH descriptor Pressure Ulcer explode all trees

\#2 pressure NEXT (ulcer ${ }^{\star}$ or sore $\left.{ }^{\star}\right)$ :ti,ab,kw

\#3 decubitus NEXT (ulcer ${ }^{\star}$ or sore*):ti,ab,kw

\#4 (bed NEXT sore*) or bedsore*:ti,ab,kw

\#5 (\#1 OR \#2 OR \#3 OR \#4)

\#6 MeSH descriptor Posture explode all trees

\#7 (reposition* or re-position*):ti,ab,kw

\#8 position*:ti,ab,kw

\#9 (turn* NEAR/5 patient $\left.{ }^{\star}\right):$ ti,ab,kw

\#10 (turn* NEAR/5 interval ${ }^{\star}$ ):ti,ab,kw

\#11 (turn* NEAR/5 frequen*):ti,ab,kw

\#12 (body NEAR/5 postur ${ }^{\star}$ ):ti,ab,kw

\#13 turning:ti,ab,kw

\#14 (pressure NEXT relie $\left.{ }^{\star}\right): t i, a b, k w$

\#15 (mobilis* or mobiliz*):ti,ab,kw

\#16 (\#6 OR \#7 OR \#8 OR \#9 OR \#10 OR \#11 OR \#12 OR \#13 OR $\# 14$ OR \#15)

\#17 (\#5 AND \#16).

We adapted this strategy to search Ovid MEDLINE, Ovid EMBASE and EBSCO CINAHL (See Appendix 1). We combined the Ovid MEDLINE search with the Cochrane Highly Sensitive Search Strategy for identifying randomised trials in MEDLINE: sensitivity- and precision-maximising version (2008 revision) (Lefebvre 2011). We combined the EMBASE and CINAHL searches with the trial filters developed by the Scottish Intercollegiate Guidelines Network (SIGN 2011).

We conducted separate searches to identify economic studies in the following databases:

1. NHS Economic Evaluation Database (2013, Issue 8);

2. Ovid MEDLINE (In-Process \& Other Non-Indexed Citations August, week 4, 2013);

3. Ovid EMBASE (1948 to 2013 week 35);

4. EBSCO CINAHL (1982 to 30 August 2013);

5. EURONHEED (http://infodoc.inserm.fr/euronheed/);

6. Health Economics Evaluations Database HEED (http://onhttp://onlinelibrary.wiley.com/book/).
We used the economics search strategy shown in Appendix 2 to search Ovid MEDLINE and adapt this strategy to search other databases.

We also searched the following clinical trials registries for details of relevant protocols and contacted the relevant research teams in November 2012:

1. Clinical trials.gov;

2. International Clinical Trials Registry Platform search Portal;

3. Australian and New Zealand Clinical Trials Registry;

4. Current Controlled Trials.

We did not restrict searches by language, study setting, date of publication or publication status. We made every effort to obtain translations of papers that were not published in English.

\section{Searching other resources}

We searched the reference lists of included studies and any systematic reviews identified by the search process and contacted corresponding authors of identified studies. Where appropriate, we contacted experts in the field (e.g. council members of the European Wound Management Association, the National Pressure Ulcer Advisory Panel, the World Union of Wound Healing Societies, and the Australian Wound Management Association) to ask for information about any unpublished studies. We included conference proceedings or programme abstracts in our search. Where we were unable to obtain details of the full study, we contacted the author(s).

\section{Data collection and analysis}

\section{Selection of studies}

Two review authors (BG, EM) independently assessed all titles and abstracts of studies retrieved from searching. Full reports of all potentially relevant trials were retrieved for further assessment of eligibility based on the inclusion criteria. Differences of opinion were resolved by consensus or referral to a third review author (WC). We recorded reasons for exclusion and were not blind study authorship.

\section{Data extraction and management}

For eligible studies, two review authors (BG, EM) independently extracted data using a pre-designed data collection tool while a third author (WC) adjudicated where there were differences of opinion. For studies where there was an economic component included, JW (Health Economist) and BG extracted the relevant data. We included studies published in duplicate, but extracted data to ensure that information was not missed and identified the primary reference for the purpose of this review. If data were missing from reports, we attempted to contact the trial authors to obtain the missing information. One review author (BG) entered the data into Review Manager 5 software (RevMan) and data were checked for accuracy by EM. Abstracted data included the following information.

1. Author, title, journal title, year of publication, country.

2. Healthcare setting.

3. Inclusion/exclusion criteria.

4. Sample size.

5. Patient characteristics by treatment group. 
6. Methods (number eligible and randomised, adequacy of randomisation, allocation concealment, blinding, completeness of follow-up).

7. Treatment of missing values (e.g. use of intention-to-treat, per protocol or other imputation method)

8. Intervention details.

9. Types of outcome measures in relation to primary (percentage of new PU) and secondary outcomes.

10.Analysis; results and conclusions relevant to review.

11.Funding sources.

For economic studies, we planned to extract additional data extract in relation to the following.

1. Estimates of specific items of resource use per person.

2. Estimates of unit costs (extracted separately to resource use).

3. Price year and currency.

4. Decision-making jurisdiction.

5. Analytic perspective.

6. A point estimate and a measure of uncertainty (e.g. standard error or confidence interval) for measures of incremental resource use, costs and cost-effectiveness, if reported.

7. Details of any sensitivity analyses undertaken, and any information regarding the impact of varying assumptions on the magnitude and direction of results.

\section{Assessment of risk of bias in included studies}

Two review authors independently assessed the risk of bias of eligible trials (BG, EM) using The Cochrane Collaboration tool for assessing risk of bias (Higgins 2011c).This tool addresses six specific domains; namely sequence generation, allocation concealment, blinding, incomplete outcome data, selective outcome reporting and other issues that may potentially bias the study (see Appendix 3 for details of the criteria on which the judgments were based). Items were rated as low risk of bias, high risk of bias or unclear (unknown) risk of bias. In assessing bias, the review authors were not blinded to the names of trial authors, institutions, or journals.

In assessing the risk of bias, we distinguished between primary outcome (proportion of participants with a new PU), secondary subjective outcomes (HRQoL, procedural pain, patient satisfaction), and the objective economic outcome. As the primary outcome for this review, regardless of how it was measured, was subject to potential observer bias, blinding of outcome assessment was particularly important. We planned to make separate judgements for secondary outcomes for the domain of incomplete outcome data. We classified trials as being at overall high risk of bias if they were rated as 'high' for any one of three key domains (allocation concealment, blinding of outcome assessors and completeness of outcome data).

Disagreements between review authors were resolved by consensus or referral to another review author (WC). Where there was a high risk of bias in any of the key domains, we endeavoured to contact the trial authors, and asked open-ended questions about the design and conduct of the study. We reported bias, and within economic evaluations, planned to use the Drummond checklist, as recommended by The Cochrane Collaboration (Shemilt 2011), to assess the methodological quality of full and partial economic evaluations.
We presented an assessment of risk of bias using 'Risk of bias' summary figures, which detail all the judgments in a cross-tabulation of study by entry. This display of internal validity indicates the weight the reader may give the results of each study. We classified studies as being at high risk of bias overall if any one of the criteria was judged to be at high risk of bias. We recorded trials as being at unclear risk of bias if authors did not report validity criteria.

\section{Measures of treatment effect}

We have reported effect estimates for dichotomous outcomes (e.g. relative proportions of people developing PU during follow up) as risk ratios (RR) with $95 \%$ confidence intervals. $R R$ is the proportion of participants developing PUs in the experimental group divided by proportion in the control group and indicates the likelihood of PU development on the experimental regimen (turning frequency or position) compared with a standard treatment. We have used the $\mathrm{RR}$ rather than odds ratio (OR), since ORs may be misinterpreted as $R R$, and can give an inflated impression of the effect size when event rates are greater than $20 \%$ (Deeks 2002). We planned to use MD as a summary statistic in meta-analysis when outcome measurements in all studies were made on the same scale.

\section{Review of economic evaluations}

We planned to present a tabled analysis of economic data in accordance with current guidance on the use of economics methods in the preparation of Cochrane reviews (Shemilt 2011). We planned to classify economic evaluations according to the framework in Drummond 2005, and to assess the methodology using the checklist published by Drummond and colleagues. We planned to tabulate the main characteristics and results of the identified economic evaluation studies, and to expand these with a narrative description.

For any included studies, given the likely lack of direct comparability in resource use and cost data between different healthcare contexts and settings, we did not intend to pool economic outcomes. Rather, we planned to incorporate a discussion of key drivers and impact of assumptions on the available economic evaluations, scenarios that are likely to lead to the most and least cost-effective use of repositioning for PUP, as well as guidance on future research that might be required to assess the economic value of repositioning as an intervention for PUP.

\section{Costs}

If we found any economic studies, all substantial costs that were observed to differ between people repositioned for PUP and people administered the comparator treatment were intended to be captured and reported as part of the review of economic evaluations.

We planned to report resource utilisation and unit costs separately, along with the currency and price year in each original study. These costs would then be converted to 2012 values by employing a webbased conversion tool that applies implicit price deflators for gross domestic product (GDP) of that currency and then converted into the currency most frequently observed in the articles reviewed using Purchasing Power Parities (PPP) (Shemilt 2010).

The main costs were likely to be those associated with the development of PUs, specialist and other practitioner costs as measured by time or number of visits, potential cost-savings from a change in the number of bed days in hospital, and costs stemming from differing rates of adverse events and complications (including proce- 
dures initiated due to the failure of wounds to heal, such as amputation). We planned to identify key cost drivers that would enable users of the review to gain a clear understanding of the nature of resource use associated with repositioning for PUP.

\section{Health state utility weights}

We planned to examine information on the change in HRQoL reported by included trials via utilities measured by a multi-attribute utility instrument (MAUI) or other approaches (such as the time trade-off, standard gamble). We planned to assess the utility data for comparability and representativeness considering issues such as the stages of PU, the patient populations, timing of the baseline point and follow-up collection, the MAUI used and the algorithm for scoring the MAUI. We planned to present a discussion of the potential impact on HRQoL attributable to the intervention as part of the review.

\section{Unit of analysis issues}

In all trials included in our review, we treated the person as the unit of analysis and we took into account the level at which randomisation occurred. For a parallel group design, we collected and analysed a single measurement for each outcome for each person. In these types of studies, it was possible that the unit of analysis was the PU rather than the individual person. We considered instances where there were multiple observations per person for the same outcome. Where this occurred we first used the PU that was the most advanced in relation to its staging. If this could not be determined, then we contacted the trial author(s).

For cluster-randomised trials that had not taken clustering into account in the study analysis, we considered adjusted sample sizes using the methods described in Chapter 16 of the Cochrane Handbook for Systematic Reviews of Interventions (Higgins 2011a). However the best estimate of a relevant intraclass correlation coefficient (ICC) for estimating the design effect was so small (0.001) that we used the original reported study data without adjustment. This ICC (0.001) was estimated from a relevant cluster trial (Moore 2011) and identical to that estimated from a falls study (similar patient group, similar context of care) (Cumming 2008) so we felt justified in this approach.

\section{Dealing with missing data}

If some outcome data remained missing despite our attempts to obtain complete outcome data from authors, we planned to perform an available-case analysis, based on the numbers of people for whom outcome data were known since this is a more conservative approach in this context than using numbers originally randomised and assuming that losses to follow up did not incur pressure injury. We also planned to conduct best-case and worst-case analysis where we needed to test the robustness of findings to different assumptions about the outcomes of people who did not contribute endpoint data. If standard deviations (SD) were missing, we planned to impute them from other studies or, where possible, computed them from standard errors (SE) using the formula $\mathrm{SD}=$ SE $x \sqrt{ }^{-} N$, where these values were available (Higgins 2011a).

\section{Assessment of heterogeneity}

We considered clinical and statistical heterogeneity in relation to the primary outcomes, PU incidence, and secondary outcomes such as HRQoL patient satisfaction, and procedural pain. For clus- ter-trials, we assessed the outcome at the same level as the group allocation (Deeks 2011).

We assessed clinical heterogeneity by examining the types of participants, and/or groups, interventions and their duration, and the outcomes of each study. If appropriate, we pooled data using metaanalysis (using RevMan 5). We did not plan to pool studies for economic outcomes as the variability in, and generalisability of, these outcomes were considered problematic.

Statistical heterogeneity was assessed visually and by using the $\mathrm{Chi}^{2}$ statistic with significance being set at $\mathrm{P}$ value less than 0.10 . In addition we investigated the degree of heterogeneity by calculating the $\mathrm{I}^{2}$ statistic (Deeks 2002). The $\mathrm{I}^{2}$ test examines the percentage of total variation across studies due to heterogeneity rather than chance. Values over $50 \%$ indicate a substantial level of heterogeneity. Where appropriate, in the absence of clinical heterogeneity and in the presence of statistical heterogeneity ( 12 greater than $60 \%)$, we used a random effects model, Where studies were sufficiently similar to consider pooling, we planned to use a fixed effect model for low to moderate levels of heterogeneity ( $1^{2}$ values between $0 \%$ and under $60 \%$ ). We did not plan to pool studies where heterogeneity exceeded 75\% (Higgins 2011b).

\section{Assessment of reporting biases}

We planned to assess potential publication bias using funnel plots and to assess funnel plot asymmetry visually (Sterne 2011).

\section{Subgroup analysis and investigation of heterogeneity}

We planned a subgroup analysis, if possible, to examine the effect of potentially influential factors on outcome, e.g. care setting and patient characteristics.

\section{Sensitivity analysis}

We planned to perform sensitivity analyses where necessary to test whether findings were robust to the method used to obtain them, and compared the results of two or more meta-analyses using different assumptions (Higgins 2011c).

\section{Presentation of results}

We planned to include the following primary and secondary outcomes (both desirable and undesirable) in the summary of findings tables:

1. development of a new PU;

2. HRQoL;

3. pain;

4. patient satisfaction;

5. costs;

6. incremental cost.

\section{RES U L T S}

\section{Description of studies}

See Characteristics of included studies; Characteristics of excluded studies; and, Characteristics of studies awaiting classification. With the exception of the TURN trial (Bergstrom), we are not aware of any relevant ongoing trials (ISRCTN register checked September, 2013). 


\section{Results of the search}

\section{Interventions search}

Electronic searches yielded 258 results of which we excluded 254 because they did not meet one or more of our inclusion criteria. We retrieved full text versions of the remaining four papers for inspection, and included three trials in the review (Defloor 2005; Moore 2011; Young 2004). See Figure 1 study flow diagram. All the included trials had been published in the last 10 years. One ongoing study was identified (Bergstrom) which will be considered for inclusion in the next update of this review. 
Figure 1. Study flow diagram for clinical studies

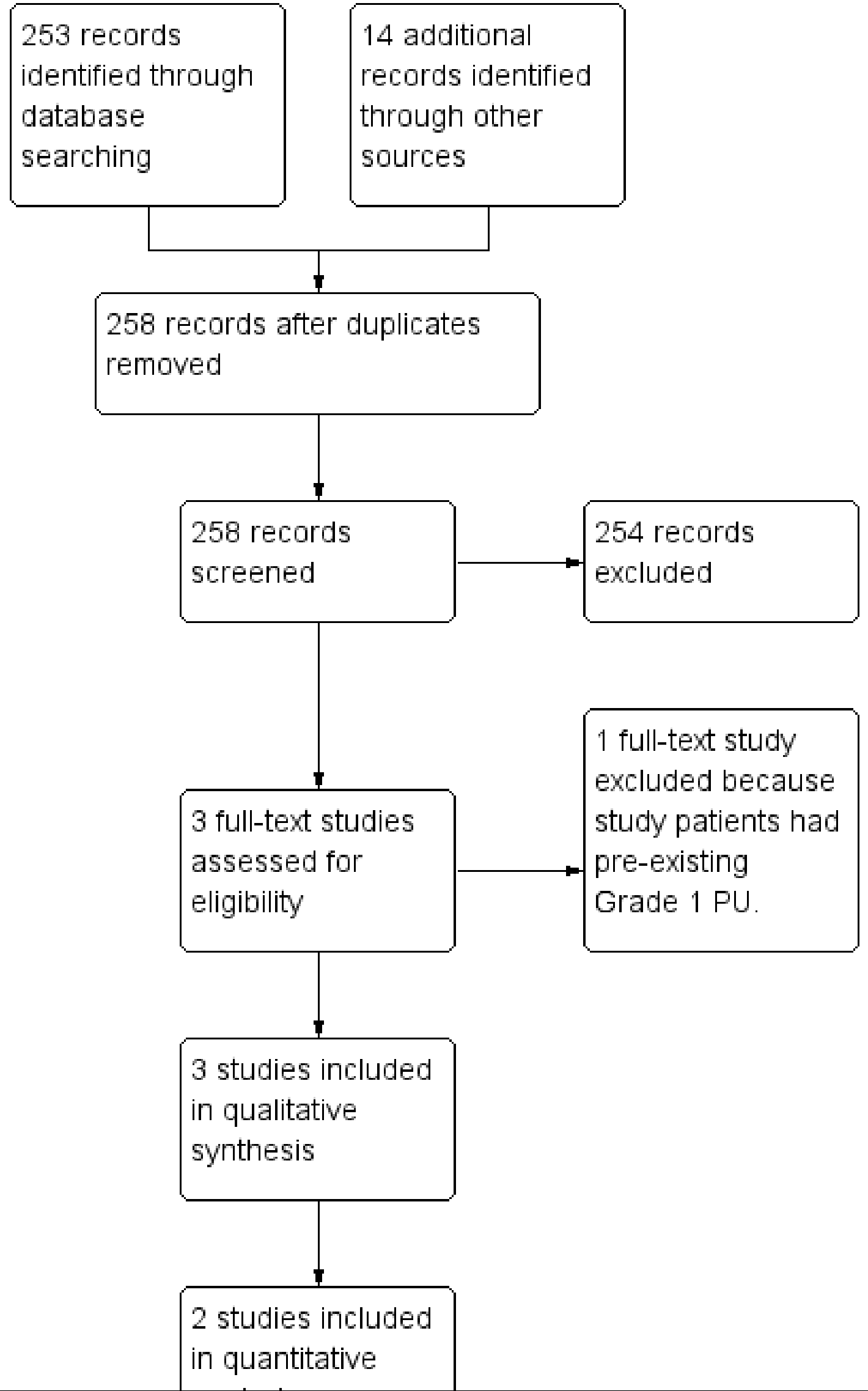




\section{Economic analysis search}

Electronic searches yielded 238 references, of which 237 were excluded because they did not meet our inclusion criteria. One eco- nomic substudy by Moore 2013 was identified. See Figure 2 study flow diagram. 
Figure 2. Study flow diagram for economic studies

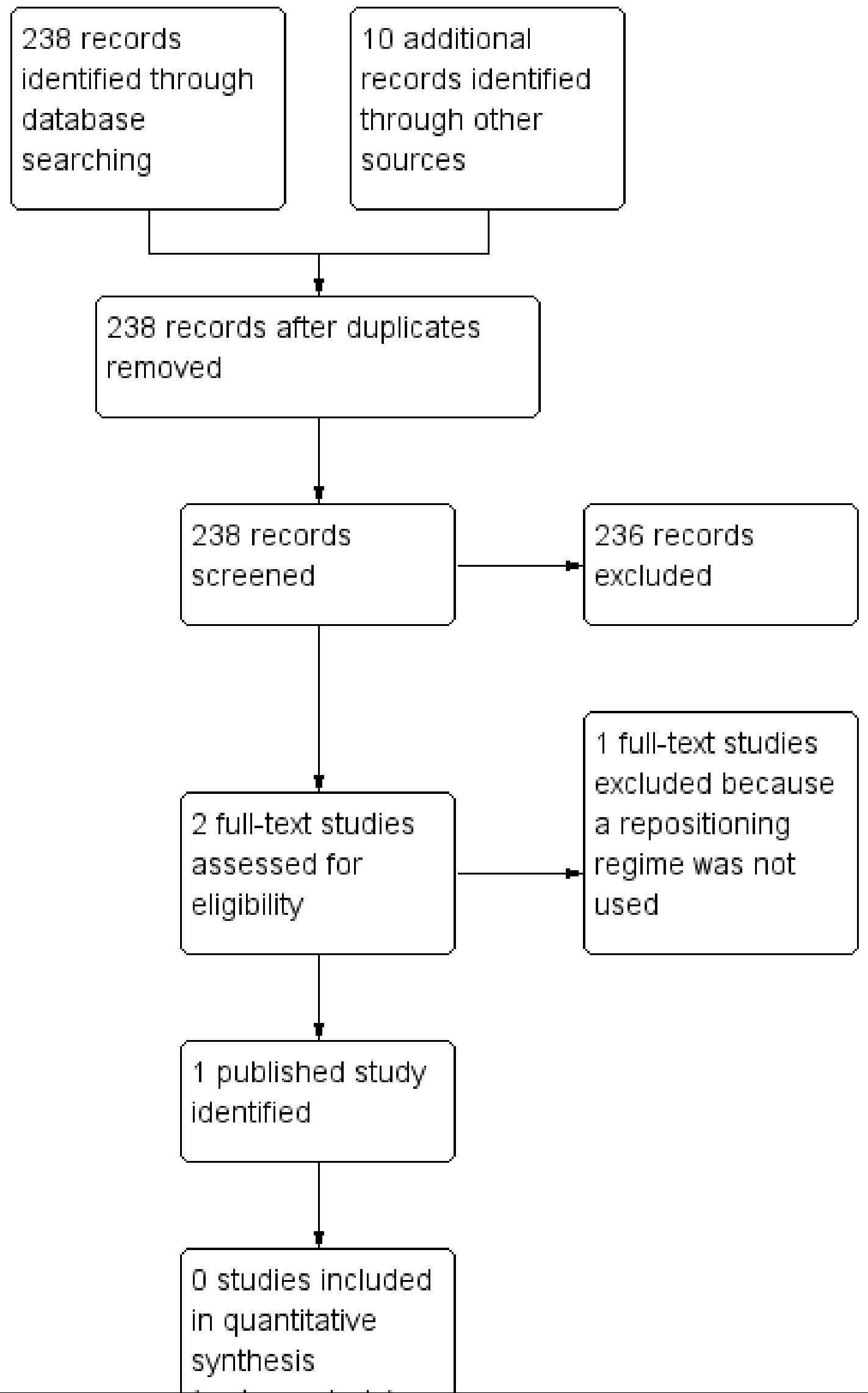




\section{Included studies}

\section{Types of participants}

We did not adjust sample sizes for clustering in the two cluster RCTs (see above) (Defloor 2005; Moore 2011). A total of 1097 participants were enrolled in the three trials included in this review (Defloor 2005; Moore 2011; Young 2004). Total numbers randomised in the included studies were 838 (Defloor 2005), 213 (Moore 2011), and 46 (Young 2004). However, in Defloor 2005 only 262 participants were randomised to arms relevant to this review meaning a total of 521 randomised participants were potentially considered here. Ultimately 502 participants were included in the analyses reported here as 19 people were lost to follow up and we conducted a complete case analysis. Within these trials the majority of participants were residents of long-term care settings (Defloor 2005; Moore 2011), whilst one small study recruited 46 participants from a single acute care facility (Young 2004). Participants in all three trials were aged over 65 years and all trials were conducted in Europe (Belgium (Defloor 2005), Ireland (Moore 2011), and Wales (Young 2004)).

\section{Types of interventions}

In two of the three trials (Moore 2011; Young 2004), a $30^{\circ}$ tilt position was compared with a standard $90^{\circ}$ supine/lateral position. Participants in both the intervention and control groups were tilted left side, back, right side, and back. Essentially, the Moore 2011 and Young 2004 trials compared the same tilts $\left(30^{\circ}\right.$ vs $\left.90^{\circ}\right)$ and the same repositioning frequency for the $30^{\circ}$ tilt. However, there was a difference in the frequency of repositioning overnight for the $90^{\circ}$ tilt groups. In the Moore 2011 trial, patients in the $90^{\circ}$ tilt group were repositioned 6-hourly overnight compared with two to 3-hourly overnight in the Young 2004 trial.

The third trial (Defloor 2005) evaluated different repositioning frequencies (2-, 3-, 4- and 6-hourly) using a semi-Fowler or lateral position, in combination with standard or viscoelastic mattresses. The participants receiving the 2 hourly and 3 hourly repositioning all received the standard hospital mattress whilst those receiving the 4 and 6 hourly repositioning received viscoelastic foam mattresses. In this study there was also a large "standard care" arm comprising 576 people allocated care based on nurses' clinical judgement (a range of support surfaces but no repositioning). We disregarded this treatment arm for the purposes of this review as it systematically differed from the other 4 arms in both the allocation of support surface and repositioning. In the other 4 groups, co-interventions such as the use of nutritional supplements, skin care and allocation of pressure relieving cushions during chair sitting were also used.

\section{Types of outcomes}

The primary outcome in each of the included trials was the proportion of participants developing a new PU (Defloor 2005; Moore 2011; Young 2004). Two trials reported the incidence of PU and included Stages 1 to 4 over a 28-day period (Defloor 2005; Moore 2011), while the third trial reported a much briefer follow-up period of 24 hours and reported only Stage 1 PU (i.e. non-blanchable erythema) (Young 2004).

\section{Excluded studies}

One trial was excluded after the full text had been screened (Vanderwee 2007). In this trial, participants who had pre-existing Stage 1 non-blanchable erythema at baseline were included, and those who did not have non-blanchable erythema were excluded. We had pre-specified that only studies where patients had no existing PU skin damage were eligible for inclusion.

\section{Risk of bias in included studies}

We present an assessment of the risk of bias using 'Risk of bias' summary figures (Figure 3 and Figure 4), which detail all of the judgements in cross-tabulations of study by entry. All three trials were at unclear or at high risk of bias. 
Figure 3. Risk of bias summary: review authors' judgements about each risk of bias item for each included study

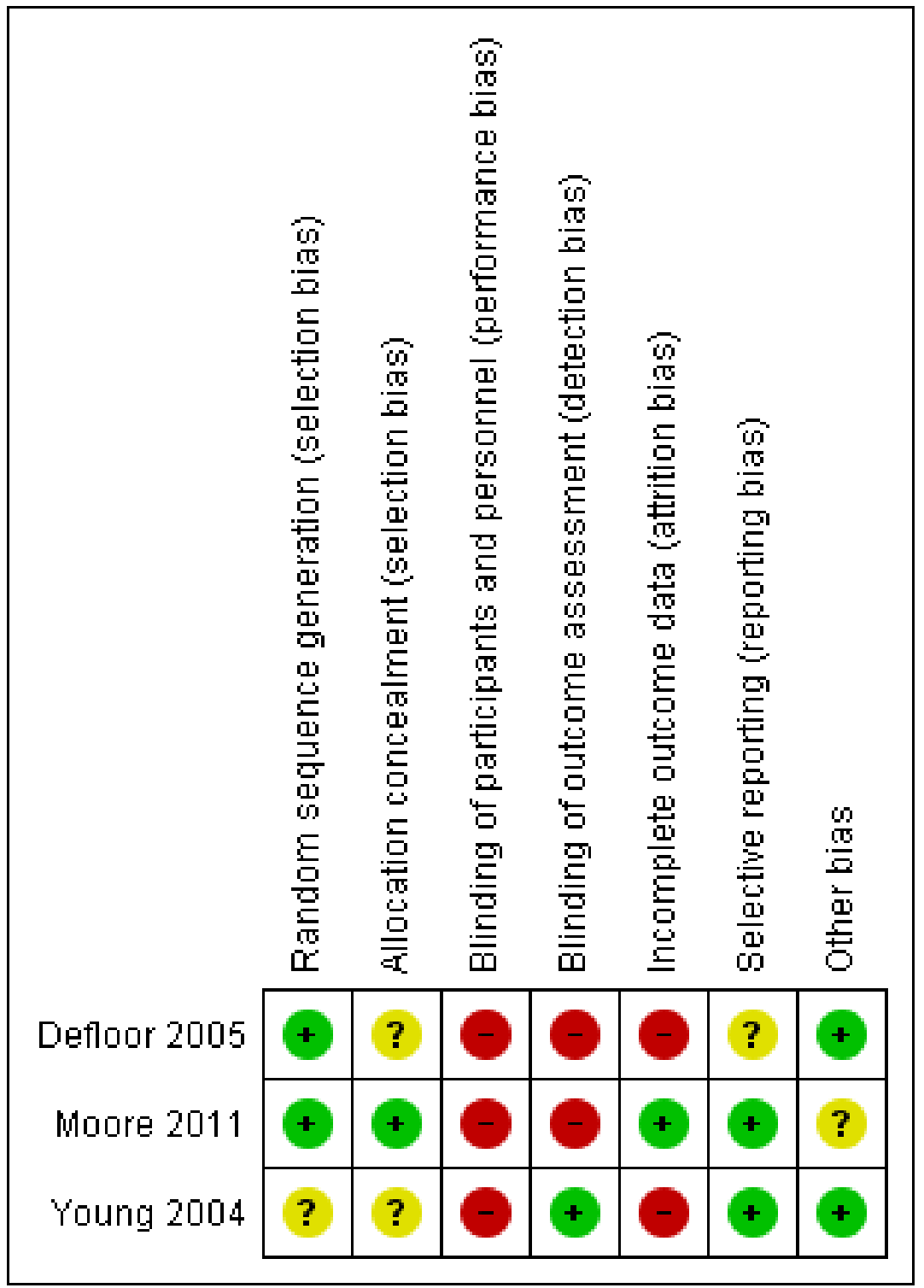


Figure 4. Risk of bias graph: review authors' judgements about each risk of bias item presented as percentages across all included studies

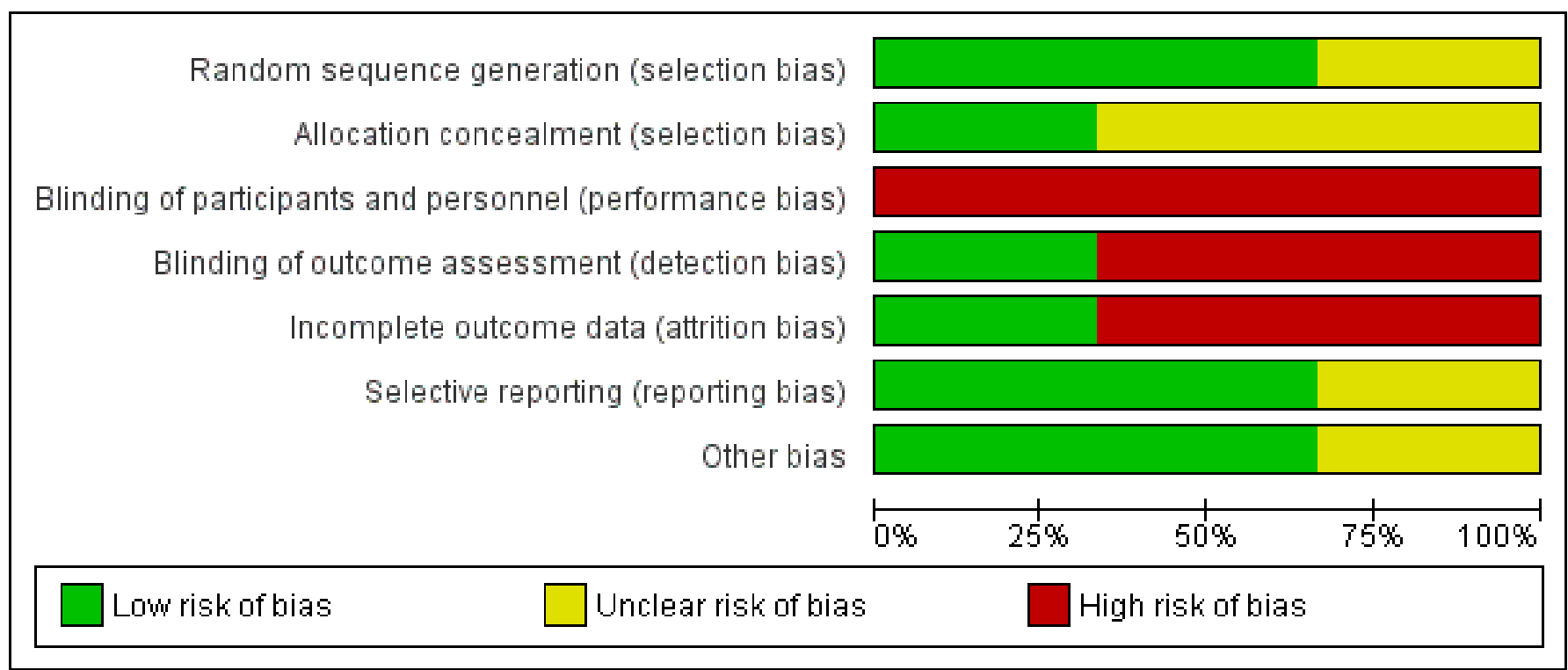

\section{Allocation}

\section{Random sequence generation}

All three trials described a process to generate the random allocation list (Defloor 2005; Moore 2011; Young 2004). Two trials used a computer-based random number generator (Defloor 2005; Moore 2011), while the Young 2004 trial used sequentially-numbered envelopes that contained a randomisation code. In the Defloor 2005 trial, randomisation also occurred over a second 4-week period. During this second period, each ward used a different prevention scheme than used in the first 4-week period.

\section{Allocation concealment}

Assessment of allocation concealment in the three included trials involved examination of whether trial authors described how the assignment sequence was protected before and until allocation. We could not adequately assess the extent of allocation concealment for the Defloor 2005 trial since the randomisation was influenced during the trial by resources and we therefore rated this "unclear". In the Young 2004 trial, the allocation was concealed from the researcher and the nurses in a sealed and sequentially numbered envelope (low risk of bias). In the Moore 2011 study, allocation concealment was achieved using remote randomisation (also low risk of bias).

\section{Blinding}

\section{Blinding of participants and personnel}

It is hard to envisage how blinding of participants and personnel to the frequency and nature of repositioning could be possible and therefore all three trials are likely to be at risk of performance bias. Two out of three trial reports did not state whether participants and nursing staff were blinded (Defloor 2005; Young 2004). The Moore 2011 trial was described as "open label", usually meaning that the participants, care givers and researchers were aware of group allocation. The Defloor 2005 and Moore 2011 trials were classified as at high risk of performance bias while the Young 2004 trial was classified as unclear risk of bias.

\section{Blinding of outcome assessors}

There was considerable variability in assessment of all grades of PU among the three trials (Defloor 2005; Moore 2011; Young 2004). Such variability is problematic, as the use of a subjective primary outcome measure is open to ascertainment bias.

Outcome measurement was not blinded in two trials (Defloor 2005; Moore 2011) and these were rated as high risk. In the Young 2004 trial, the outcome assessor was "unaware" of group allocation, as the positioning aids (pillows) were removed from under the patient prior to outcome measurement (low risk). Only Moore 2011 considered the reliability of outcome using several outcome assessors to minimise this form of bias. However, inter-rater reliability data were not presented.

\section{Incomplete outcome data}

Assessment of whether incomplete outcome data had been adequately addressed in each trial involved examining whether reasons for attrition or exclusion were reported, whether there was re-inclusion of participants, and whether completeness of data for each main outcome was described. In two of the three trials (Defloor 2005; Young 2004), participants were excluded from the analysis in sufficient numbers to threaten bias. Defloor 2005 excluded $77(9.2 \%)$ of 838 randomised participants from the analysis, and in the Young 2004 trial, seven (15.2\%) of the 46 randomised participants were excluded; two due to death (both in the control group) and five in the experimental group, who were unable to tolerate the intervention and for whom outcome data collection then ceased. For both the Young 2004 and Defloor 2005 trials, we conducted a complete case analysis (which makes no assumption about the outcomes for patients lost to follow up as this was felt more conservative than analysing losses as if they had not sustained pressure injury). Attrition bias and lack of intention-to-treat analysis were con- 
tributing factors to incomplete outcome data. In Moore 2011, all randomised participants were included in the analysis.

\section{Selective reporting}

Each study reported all pre-specified outcomes - as defined in the papers - in the results. No published protocol was available for any of these trials.

\section{Other potential sources of bias}

We planned to assess potential publication bias using funnel plots and to assess funnel plot asymmetry visually, however, as only three studies were included in this review, this was not appropriate (Sterne 2011).

\section{Effects of interventions}

\section{Comparison 1: frequencies of repositioning (one trial)}

One cluster randomised trial (Defloor 2005) was included in this comparison however we did not adjust the data for clustering as the ICC of 0.001 (from Moore 2011 and Cumming 2008) was so small as to make no difference.

\section{Primary outcomes}

The proportion of new pressure ulcers of any grade, stage or category

In the Defloor 2005 trial, various repositioning regimens of different frequencies (2-, 3-, 4- and 6-hourly), positions (i.e. semi-Fowlers and lateral), and support surfaces (i.e. viscoelastic and standard mattresses) were compared.

For the purposes of this review we compared the outcomes for repositioning frequency where the support surface was the same for both groups i.e., 2-hourly vs. 3-hourly repositioning (all on the standard hospital mattress) and 4-hourly vs. 6-hourly repositioning (all on the viscoelastic foam mattress). On the standard hospital mattress, 39/63 (62\%) participants receiving 2 hourly repositioning developed a pressure ulcer of any severity compared with 40/58 (69\%) receiving 4-hourly repositioning (RR $0.90,95 \% \mathrm{Cl} 0.69$ to 1.16 ) (Analysis 1.1).

For participants nursed on viscoelastic foam mattresses, 30/66 (46\%) of participants receiving 4-hourly repositioning developed a pressure ulcer of any severity compared with 39/63 (62\%) of those receiving 6-hourly repositioning ( $\mathrm{RR} 0.73,95 \% \mathrm{Cl} 0.53$ to 1.02 ) (Analysis 2.1).

\section{The proportion of new pressure ulcers category 2 to 4}

We also examined whether there was a treatment effect when only breaks in the skin (category 2 to 4 ulcers) were analysed however we did not pre-specify this analysis in our protocol and the results are merely exploratory.

On the standard hospital mattress, 9/63 (14\%) of participants receiving 2 hourly repositioning developed an ulcer of Category 2 and above compared with $14 / 58$ participants $(24 \%)$ receiving 3-hourly repositioning (RR $0.59,95 \% \mathrm{Cl} 0.28$ to 1.26 ) (Analysis 1.2 ). On the viscoelastic foam mattress, 2/66 (3\%) participants receiving 4-hourly repositioning developed an ulcer of Category 2 or above compared with 10/63 (16\%) receiving 6-hourly repositioning (RR $0.19,95 \% \mathrm{Cl}$ 0.04 to 0.84 ) (Analysis 2.2).

\section{Comparison 2: different positions for repositioning}

\section{Primary outcomes}

The proportion of new pressure ulcers of any grade, stage or category (two trials)

Both trials reported this outcome (Moore 2011; Young 2004).

Moore 2011 examined the use of $30^{\circ} 3$-hourly tilt (overnight) compared with repositioning 6-hourly $90^{\circ}$ tilt (overnight) in a study involving 259 randomised ( 252 analysed) participants. The incidence of pressure ulcers (Categories 1 and 2) was significantly lower in the $30^{\circ}$ tilt group (RR $0.27,95 \% \mathrm{Cl} 0.08,0.91$ ) compared with the $90^{\circ}$ tilt group (Analysis 3.1). This study was at high risk of bias due to unblinded outcome assessment.

In the small trial by Young 2004 (46 randomised, 39 analysed participants), the main outcome was Category/Stage 1 non-blanchable erythema, and the follow-up period was 24 hours. A 3-hourly $30^{\circ}$ tilt compared with a 3 -hourly $90^{\circ}$ lateral (overnight) and supine position (overnight) was used. There was no statistically significant difference in risk of pressure ulceration (RR $1.37,95 \% \mathrm{Cl} 0.25$ to 7.41) (Analysis 3.1) however this comparison is grossly underpowered with only 5 events.The trials of Moore 2011 and Young 2004 compared the same tilts $\left(30^{\circ}\right.$ vs $\left.90^{\circ}\right)$ using similar repositioning frequencies; 3-hourly for the $30^{\circ}$ tilt; 6-hourly overnight for the $90^{\circ}$ tilt in Moore 2011; and 2- to 3-hourly overnight in the Young 2004 trial therefore we pooled them using a random effects model (moderate to high heterogeneity, $1^{2}=69 \%$ ). Overall there was no difference in the risk of Category/Stage 1 or 2 pressure injury (persistent erythema) between $30^{\circ}$ and $90^{\circ}$ tilts however this comparison is at risk of a Type II error due to the lack of statistical power (pooled RR 0.62 , $95 \% \mathrm{Cl} 0.10$ to 3.97) (Analysis 3.1).

\section{Secondary outcomes}

\section{Health-related quality of life (HRQOL)}

No trial reported health-related quality of life (HRQoL).

\section{Procedural pain}

No trial reported procedural pain.

\section{Patient satisfaction}

No trial reported patient satisfaction.

\section{Cost}

One within-trial cost evaluation by Moore 2013 is included in this review. Moore 2013 performed a cost-effectiveness analysis based on data derived from their cluster randomised controlled trial (Moore 2011) comparing 3-hourly repositioning using the $30^{\circ}$ tilt overnight ( $n=99$, unadjusted for clustering) with standard care consisting of 6 hourly repositioning using the $90^{\circ}$ lateral rotation overnight $(n=114$, unadjusted for clustering), in participants recruited from 12 long term aged-care facilities in Ireland.

Moore 2013 compared the nursing time costs and incidence of PU development over the four week trial period. Nurse time was calculated from information recorded in the clinical study indicating number of turns per patient, nurses per turn, and nurse time per turn. A unit cost of $€ 23.94$ per nurse hour was then applied, based on the rate for a staff nurse scale point 8 in mid-2009. Efficacy was measured as PU incidence (the primary outcome of the clinical trial), 
which would appear to be represented as the number of patients developing a new PU during the four week trial period. Moore 2013 also reported some data for the total cost of dressings for treating PUs that developed during the trial, but did not report a unit cost and did not include dressing costs in the incremental analysis.

\section{Incremental cost per event avoided}

The $30^{\circ} 3$-hourly tilt positioning intervention was reported to be cost saving in nurse time compared with standard care (mean nurse time cost per patient $€ 206.6$ vs $€ 253.1$, incremental difference $€-46.5$; $95 \% \mathrm{Cl}$ : $€-1.25$ to $€-74.60$ ) (Moore 2013). The intervention dominated the control in terms of cost-effectiveness, since the trial also found the intervention to be more effective than the control. The lower nurse time cost for the intervention group despite the greater turning frequency was due to the lower time and reduced number of nurses required for each turn.

Given the intervention dominated the control, it was unnecessary for Moore 2013 to estimate an incremental cost-effectiveness ratio although they did. There is some inconsistency in the reporting and interpretation of the incremental analysis made by Moore 2013 , leading to a lack of clarity in the paper around the estimated cost-effectiveness. Moore 2013 suggest their efficacy outcome in the incremental analysis as both "patient free of PU" and "PU avoided". The rationale for changing between outcome measures of "patient free of PU" and "PU avoided" is unclear. Nevertheless, in this instance these outcome measures would appear to be equivalent since the number of patients developing an ulcer and the number of PUs developing during the trial was the same $(n=16)$ (Moore 2011). Moore 2013 reported the incremental cost per patient free of PU $(-€ 73.40)$ and per pressure ulcer avoided ( $-€ 547.00)$. Although not explicitly stated, the estimated incremental cost effectiveness ratios appear to be intended to represent an incremental cost per additional incremental outcome. However, these values are inconsistent with each other, given the incidence of PUs developing was the same in the trial (Moore 2011) regardless of whether defined as number of patients developing PU or number of PUs developing during the trial. Further, neither of these values could be confirmed from the data provided in the main body of the Moore 2013 paper. The former value ( $€ 73.40$ per patient free of $P U$ ) appears to have been incorrectly estimated from the data presented in the paper. The latter value of - $€ 547$ per (additional) PU avoided is consistent with the efficacy data presented in the abstract, but the efficacy data presented in the abstract is inconsistent with efficacy data presented in the main body of the report, and does not precisely match the efficacy data provided in the original clinical trial report (Moore 2011).

Despite this limitation in interpretation, the reported findings suggest that for every 100 patients treated with the 3-hourly repositioning intervention rather than standard care, $€ 4,650$ would be saved in nurse time costs and an additional 8 patients would avoid a PU. Moore 2013 concluded that repositioning every 3 hours using the $30^{\circ}$ tilt is less costly in terms of nursing time and more effective than standard care involving repositioning every 6 hours using $90^{\circ}$ tilt.

\section{DISCUSSION}

\section{Summary of main results}

\section{The proportion of new pressure ulcers of any grade, stage or category}

The main aim of this systematic review was to present and appraise all existing evidence regarding the relative effectiveness of repositioning on the prevention of PUs in adults. There is limited evidence, with only three small trials and data from a total of 502 participants contributing to this analysis. Moreover the three trials were at high risk of bias.

The results of the review are that we have insufficient evidence to draw a reliable conclusion of whether more frequent repositioning (in this review we report 2-hourly vs. 3-hourly, and 4-hourly vs. 6hourly) or different positions (the $30^{\circ}$ tilt compared with the $90^{\circ}$ lateral position) are more effective in reducing pressure damage. The lack of statistical power means we cannot say there is no benefit associated with more frequent repositioning since in each comparison the proportion of people developing pressure ulcers was lower in the groups receiving more frequent changes of position but the differenced did not reach conventional levels of statistical significance and so may be chance rather than "real" differences. There was a statistically significant reduction in pressure ulcers of Category 2 and above with 4-hourly repositioning compared with 6hourly (Defloor 2005) however we did not prespecify this outcome and this finding is exploratory.

It is noteworthy that in Defloor 2005, 46\% of participants receiving 4-hourly repositioning and $62 \%$ of those receiving 6 -hourly developed pressure damage, despite being nursed on viscoelastic foam mattresses. This suggests that although another Cochrane review (McInnes 2011) found that more advanced foam mattresses reduce pressure damage relative to the standard hospital mattress, high rates of pressure damage are still observed and careful monitoring of skin condition is required.

Repositioning regimens are widely used and recommended in best practice guidelines (European Pressure Ulcer Advisory Panel 1998; Australian Wound Management Association 2011), however there is limited empirical evidence of their effect on the prevention of pressure ulcers. That said, the theoretical rationale for repositioning (to reduce isolated tissue ischaemia by relieving pressure) makes physiological sense. However current evidence does not enable conclusions to be drawn regarding the optimum position or frequency of re-positioning. The lack of experimental evidence for repositioning per se, or for specific positions and frequencies, should not be interpreted as evidence of ineffectiveness.

\section{Overall completeness and applicability of evidence}

There was limited evidence available to assess the benefits of different regimens for the prevention of pressure ulcers. Overall the three studies in this review had sample sizes resulting in a lack of statistical power to detect a treatment effect if it exists. Small sample sizes increase the risk of Type 2 errors and reduce the precision of the estimates.

There was wide variation in sample sizes among the trials. Only one of the trials was conducted in an acute care setting and included only hospital patients over the age of 65 years (Young 2004). The primary study outcome reported in all three trials was the incidence 
of pressure ulcers. None of the included trials examined outcomes such as pain, quality of life or participant satisfaction. Only one trial author performed a parallel economic substudy (Moore 2013).

The focus of the interventions of the three trials that met our inclusion criteria varied, with two trials using tilts and three-hourly overnight repositioning (Moore 2011; Young 2004), while the third used various repositioning frequencies and positions in combination with different types of mattresses (Defloor 2005). Another limitation was the inconsistency in follow-up periods, which ranged between 24 hours (Young 2004) to 28 days (Defloor 2005 and Moore 2011). All three trials were conducted in Europe which may limit the generalisability of the findings. Furthermore, technological developments in mattress composition and materials, as well as bed design, has occurred since the two earliest studies were conducted, which also limits the external validity of these results, as it is likely that other support surfaces are now in use.

\section{Quality of the evidence}

The quality of the body of evidence has been appraised using the GRADE approach in relation to study limitations, inconsistency of results,indirectness, imprecision and risk of bias, as specified in the Handbook (Schünemann 2011) and a Summary of Findings Table will be included in the next update. There is very low quality of evidence from the three trials that assessed the use of different repositioning regimens. The evidence was downgraded because of the low number of participants with consequent imprecision together with high risk of bias. The primary outcome, pressure ulcer development, requires a subjective judgement of whether tissue damage has occurred (at least for Grade 1 pressure ulcer) and only one study (Young 2004) used blinded outcome assessment.

\section{Potential biases in the review process}

We followed clearly defined, pre-specified procedures to prevent potential bias in the review process. A comprehensive and systematic literature search was conducted, that was both transparent and reproducible. That notwithstanding, it is possible that we missed trials published in journals that were outside our search strategy.

Whilst we had intended to conduct a sensitivity analysis to test the robustness of the results to different assumptions about the outcomes of people who were lost to follow up, we felt that this was not necessary due to the poor volume and quality of the evidence and our consequent inability to draw any conclusions (no sensitivity analysis would help in this regard).

None of the review authors has any conflict of interest.

\section{Agreements and disagreements with other studies or reviews}

Our results are consistent with others' assessment of the evidence for repositioning. The systematic review by Reddy 2006, was published before one of our included trials, Moore 2011, was undertaken. The results of the review by Reddy 2006 suggested that the evidence around repositioning remains somewhat inconclusive, and the methodology for PUP trials sub optimal.

\section{AUTHORS' CONCLUSIONS}

\section{Implications for practice}

There is currently insufficient evidence that the $30^{\circ}$ tilt is more effective than the $90^{\circ}$ tilt (two trials, only 21 events in total). Repositioning in some form is recommended in all clinical guidelines though implementation is probably variable and highly dependent on the available resources (particularly staffing levels). It is noteworthy that more recent clinical guidelines no longer advocate repositioning patients every two hours (European Pressure Ulcer Advisory Panel 2009; National Pressure Ulcer Advisory Panel 2007).

It is surprising that, to date, there is little evidence available from RCTs that addresses the question of whether repositioning patients does decrease the risk of acquiring pressure ulcers. The lack of evidence is a cause for concern considering that estimates of incidence of hospital-acquired pressure ulcers range from less than $3 \%$ to over 30\% of patients (Mulligan 2011; Queensland Health 2008; Schuurman 2009; Nixon 2006).

The aetiology of pressure ulcer development is linked to localised vascular obstruction that reduces capillary blood flow to the skin surface area (European Pressure Ulcer Advisory Panel 2009). Thus, there are reasonable grounds to expect that repositioning hospitalised patients will minimise the risk of oxygen deprivation and nutrients that are required for tissue repair. However, the optimal frequency with which this should occur must consider the other negative effects of turning such as the potential for sleep disruption, heightened increases in patients' pain perception and, for nurses, musculoskeletal injuries

\section{Implications for research}

There is an urgent need for appropriately-powered, high-quality, multicentre trials to evaluate the clinical and cost effectiveness of repositioning regimens on the prevention of pressure ulcers. The modest sample sizes in the trials reviewed is a major limitation. Thus in future trials, larger numbers of participants are needed, particularly if cluster trials are conducted. Two of the thee trials reviewed here were conducted in long-term care settings, therefore, there is a need to use acute care settings to address the rise in prevalence of hospital acquired pressure ulcers (Mulligan 2011). Consistency in the measures used to classify pressure ulcers of any severity is essential. Given the high costs associated with the prevention and treatment of pressure ulcers, priority should be given to robust RCTs with economic evaluations. Trialists should consider comparisons of:

1. the repositioning frequencies and optimal positioning;

2. the effects of repositioning in patients with limited mobility (e.g. paraplegia);

3. the economic costs (including incremental costs) of PUs; and,

4. the economic and social impacts of PUs on patients' HRQoL using valid and reliable HRQoL measures.

Good quality trials also need to address the methodological limitations identified in the trials of this review. Trialists must ensure transparency of research process and adhere to the CONSORT statement for reporting RCTs (The CONSORT Statement 2010). To minimise the sources of bias, trialists need to pay careful attention to elements of research design and execution with regard to allocation concealment, randomisation, blinding, and participant attri- 
tion (Polit 2010). For instance, having an observer who is blinded to the outcome perform the outcome assessment. If cluster-RCTs are used, trialists need also to consider the potential for bias in terms of selection bias, baseline comparability, analysis, and loss of clusters (Higgins 2011a).

\section{ACKNOWLEDGEMENTS}

The authors would like to thank the following referees: Wounds Group Editors Nicky Cullum and Andrea Nelson; Trials Search Co- odinator Ruth Foxlee; Statistical Consultant Giovanni Casazza; and, Expert Referees Zena Moore and Carol Dealey.The authors also thank Ms Jodie Vickery from Griffith University for assistance with selection of the economic studies and Elizabeth Royle for copy editing. 


\section{RE F E R E N C E S}

\section{References to studies included in this review}

Defloor 2005 \{published data only\}

Defloor T, De Bacquer D, Grypdonck MH. The effect of various combinations of turning and pressure reducing devices on the incidence of pressure ulcers. International Journal of Nursing Studies 2005;42(1):37-46.

Moore 2011 \{published data only (unpublished sought but not used)\}

Moore Z, Cowman S, Conroy RM. A randomised controlled clinical trial of repositioning, using the $30^{\circ}$ tilt, for the prevention of pressure ulcers. Journal of Clinical Nursing 2011;20(17-18):2633-44.

\section{Young 2004 \{published data only\}}

Young T. The 30 degree tilt position vs the 90 degree lateral and supine positions in reducing the incidence of non-blanching erythema in a hospital inpatient population: a randomised controlled trial. Journal of Tissue Viability 2004;14(3):88, 90, 92-6.

\section{References to studies excluded from this review}

Vanderwee 2007 \{published data only\}

Vanderwee K, Grypdonck MHF, De Bacquer D, Defloor T. Effectiveness of turning with unequal time intervals on the incidence of pressure ulcer lesions. Journal of Advanced Nursing 2007;57(1):59-68.

\section{References to ongoing studies}

Bergstrom \{unpublished data only\}

TURN Study. Ongoing study Started in 2008 and completed in June 2011.

\section{Additional references}

\section{Allman 1995}

Allman RM, Goode PS, Patrick MM, Burst N, Bartolucci AA. Pressure ulcer risk factors among hospitalised patients with activity limitation. JAMA 1995;273:865-70.

\section{Allman 1997}

Allman RM. Pressure ulcer prevalence, incidence, risk factors, and impact. Clinics in Geriatric Medicine 1997;13(3):421-36.

\section{Australian Institute of Health and Welfare 2009}

Australian Institute of Health and Welfare. Australian Hospital Statistics 2007-08. Health services series no. 33. Cat. No. HSE 71. Report. Canberra: Australian Governement, 2009.

\section{Australian Safety and Compensation Council 2009}

Australian Safety and Compensation Council. The costs of workrelated injury and illness for Australian employers, workers and the community. ASCC. Canberra, 2009.

\section{Australian Wound Management Association 2011}

Australian Wound Management Association. Pan Pacific clinical practice guideline for the prevention and management of pressure Injury. Clinical Guideline October 2011.

\section{Bennett 2004}

Bennett G, Dealey C, Posnett J. The cost of pressure ulcers in the UK. Age and Ageing 2004;33(3):230-5.

\section{Braden 1987}

Braden BJ, Bergstrom N. A conceptual scheme for the study of the aetiology of pressure sores. Rehabilitation Nursing 1987;12:8-16.

\section{Braden 2005}

Braden BJ, Maklebust J. Preventing pressure ulcers with the Braden scale: an update on this easy-to-use tool that assess a patient's risk. American Journal of Nursing 2005;105(5):70-2.

\section{Brandeis 2001}

Brandeis GH, Berlowitz DR, Katz P. Are pressure ulcers preventable? A survey of experts. Advances in Skin and Wound Care 2001;14(5):244-8.

\section{Bureau of Labor Statistics 2002}

United States Department of Labor. Case and demographic characteristics for work-related injuries and illnesses involving days away from work. Resource table 10: detailed occupation by selected parts of body affected. Report. Canberra, 2002.

\section{Buss 2002}

Buss I, Halfens R, Abu-Saad H. The most effective time interval for repositioning subjects at risk of pressure sore development. Rehabilitation Nursing 2002;27(2):59-66.

\section{Carskadon 2005}

Carskadon MA, Dement WC. Normal human sleep: an overview. In: Kryger, MH, Roth T, Dement WC editor(s). Principles and Practice of Sleep Medicine. 4th Edition. Philadelphia: Elsevier Sanders, 2005.

\section{Catania 2007}

Catania K, James P, Moran M. PUPPI: The Pressure Ulcer Prevention Protocol Interventions. American Journal of Nursing 2007;107(4):44-52.

\section{Cumming 2008}

Cumming RG, Sherrington C, Lord SR, Simpson JM, Vogler C, Cameron ID, Naganathan V, Prevention of Older People's Injury Falls Prevention in Hospitals Research Group. Cluster randomised trial of a targeted multifactorial intervention to prevent falls among older people in hospital.. BMJ 2008;336:758.

\section{Dawson 2007}

Dawson A, McLennan S, Schiller S, Jull GA, Hodges PW, Stewart S. Interventions to prevent back pain and back injury in nurses: a systematic review. Occupational and Environmental Medicine 2007;64:642-50. 


\section{Deeks 2002}

Deeks J. Issues in the selection of a summary statistic for meta analysis of clinical trials with binary outcomes. Statistics in Medicine 2002;21(1):575-600.

\section{Deeks 2011}

Deeks JJ, Higgins JPT, Altman DG, on behalf of the Cochrane Statistical Methods Group and the Cochrane Bias Methods Group (Editors). Chapter 9: Analysing data and undertaking meta-analyses. In Higgins JPT, Green S (editors). Cochrane Handbook for Systematic Reviews of Interventions Version 5.1.0 [updated March 2011]. The Cochrane Collaboration, 2011. Available from www.cochrane-handbook.org.

\section{Defloor 2000}

Defloor T. The effect of position and mattress on interface pressure. Applied Nursing Research 2000;13:2-11.

\section{Drummond 2005}

Drummond MF, Sculpher MJ, Torrance GW, O'Brien BJ, Stoddart GL. Methods for the Economic Evaluation of Health Care Programs. 3rd Edition. Oxford: Oxford University Press, 2005.

\section{European Pressure Ulcer Advisory Panel 1998}

European Pressure Ulcer Advisory Panel. Policy statement on the prevention of pressure ulcers. British Journal of Nursing 1998;7(7):888-90.

\section{European Pressure Ulcer Advisory Panel 2009}

European Pressure Ulcer Advisory Panel and National Pressure Ulcer Advisory Panel. Treatment of pressure ulcers: quick reference guide. www.npuap.org 2009.

\section{Exton-Smith 1961}

Exton-Smith AN, Sherwin RW. The prevention of pressure sores: significance of spontaneous bodily movements. Lancet 1961;2:1124-6.

\section{Higgins 2011a}

Higgins JPT, Deeks JJ, Altman DG (editors). Chapter 16: Special topics in statistics. In: Higgins JPT, Green S editor(s). Cochrane Handbook for Systematic Reviews of Interventions. Version 5.1.0. [updated March 2011]. The Cochrane Collaboration, 2011.

\section{Higgins 2011b}

Higgins JPT, Deeks JJ. Chapter 7: Selecting studies and collecting data. In Higgins JPT, Green S (editors). Cochrane Handbook for Systematic Reviews of Interventions Version 5.1.0 [updated March 2011]. The Cochrane Collaboration, 2011. Available from www.cochrane-handbook.org.

\section{Higgins 2011c}

Higgins JPT, Altman DG, on behalf of the Cochrane Statistical Methods Group and the Cochrane Bias Methods Group (editors). Chapter 8: Assessing risk of bias in included studies. In Higgins JPT, Green S (editors). Cochrane Handbook for Systematic Reviews of Interventions Version 5.1.0 [updated March 2011]. The Cochrane Collaboration, 2011.

\section{Humphries 2008}

Humphries J. Sleep disruption in hospitalised adults. MedicalSurgical Nursing 2008;17(6):391-5.

\section{Institute for Healthcare Improvement 2008}

Institute for Healthcare Improvement. Getting started kit: prevent pressure ulcers how-to guide 5 million lives campaign. Available at http://www.in.gov/isdh/files/ IHI_PU_Getting_Started_Supplement_for_Rural_Hospitals.pdf 2008.

\section{Jalali 2005}

Jalali R, Rezaie M. Predicting pressure ulcer risk: comparing the predictive validity of 4 scales. Advances in Skin and Wound Care 2005;18(2):92-7.

\section{Krapfl 2008}

Krapfl LA, Gray M. Does regular repositioning prevent pressure ulcers?. Journal of Wound, Ostomy and Continence Nursing 2008;35(6):571-7.

\section{Lefebvre 2011}

Lefebvre C, Manheimer E, Glanville J. Chapter 6: Searching for studies. In: Higgins JPT, Green S (editors). Cochrane Handbook for Systematic Reviews of Interventions Version 5.1.0 [updated March 2011]. The Cochrane Collaboration, 2011. Available from www.cochrane-handbook.org.

\section{Lindgren 2004}

Lindgren M, Unosson M, Fredrikson M, Ek AC. Immobility--a major risk factor for development of pressure ulcers among adult hospitalised patients: a prospective study. Scandinavian Journal of Caring Sciences 2004;18(1):57-63.

\section{Manorama 2010}

Manorama AA, Baek S, Vorro J, Sikorskii A, Bush TR. Blood perfusion and transcutaneous oxygen level characterizations in human skin with changes in normal and shear loads-implications for pressure ulcer formation. Clinical Biomechanics 2010;25(8):823-8.

\section{McInnes 2011}

McInnes E, Jammali-Blasi A, Bell-Syer S, Dumville J, Cullum N. Support surfaces for pressure ulcer prevention. Cochrane Database of Systematic Reviews 2011, Issue 4. [DOI: 10.1002/14651858.CD001735.pub4]

\section{Moore 2013}

Moore Z, Cowman S, Posnett J. An economic analysis of repositioning for the prevention of pressure ulcers. Journal of Clinical Nursing 2013;22:2354-60.

\section{Mulligan 2011}

Mulligan S, Prentice J, Scott L. WoundsWest Wound Prevalence Survey 2011 State-wide Overview Report. Ambulatory Care Services, Department of Health: Perth, Western Australia. 2011:1-41.

\section{National Pressure Ulcer Advisory Panel 2007}

NPUAP pressure ulcer staging and 2007 update. National Pressure Ulcer Advisory Panel 2007. 


\section{Nixon 2006}

Nixon J, Nelson EA, Cranny G, Iglesias CP, Hawkins K, Cullum NA, et al. Pressure relieving support surfaces: a randomised evaluation. Health Technology Assessment 2006;10(22):1-180.

\section{Norton 1962}

Norton D, McLaren R, Exton-Smith AN. An Investigation of Geriatirc Nursing Problems in Hospital. New York: Churchill Livingstone, 1962.

\section{NPUAP 2009}

National Pressure Ulcer Advisory Panel \& European Pressure Ulcer Advisory Panel. Prevention and treatment of pressure ulcers: clinical practice guideline. NPUAP \& EPUAP. Washington, 2009.

\section{Palmen 1987}

Palmen NGM. Prevention of pressure sores in a general hospital: a study into the effect of a nursing intervention focusing on pressure sore prevention. Unpublished Masters Thesis, Maastricht University 1987.

\section{Polit 2010}

Polit D, Gillespie B. Intention-to-treat in randomized controlled trials: recommendations for a total trial strategy. Research in Nursing \& Health 2010;33:355-68.

\section{Queensland Health 2008}

Queensland Health. Pressure ulcer prevalence audit, 2008. Queensland Health Patient Safety Centre 2008.

\section{Queensland Health 2009}

Queensland Health. Pressure ulcer prevention and management resource guidelines. The State of Queensland. Queensland Health, Brisbane 2009.

\section{Raymond 2004}

Raymond I, Ancoli-Israel S, Choiniere M. Sleep disturbances, pain and analgesia in adults hospitalised for burn injuries. Sleep Medicine 2004;5:551-9.

\section{Reddy 2006}

Reddy M, Gill S, Rochon P. Preventing pressure ulcers: A systematic review. JAMA 2006;296(8):974-84.

\section{Schuurman 2009}

Schuurman JP, Schoonhoven L, Defloor T, Van Engelshoven I, Van Ramshorst B, Buskens E. Economic evaluation of pressure ulcer care: a cost minimization analysis of preventative strategies. Nurse Economics 2009;27(6):390-400.

\section{Schünemann 2011}

Schünemann HJ, Oxman AD, Higgins JPT, Vist GE, Glasziou P, Guyatt GH. Chapter 11. Presenting results and 'Summary of findings' tables. In Higgins JPT, Green S (editors). Cochrane Handbook for Systematic Reviews of Interventions Version 5.1.0 [updated March 2011]. The Cochrane Collaboration, 2011. Available from www.cochrane-handbook.org.

\section{Shemilt 2010}

Shemilt I, Thomas J, Morciano M. A web-based tool for adjusting costs to a specific target currency and price year. Evidence and Policy 2010;6:51-9.

\section{Shemilt 2011}

Shemilt I, Mugford M, Byford S, Drummond M, Eisenstein E, Knapp M. Chapter 15: Incorporating economics evidence. In: Higgins JPT, Green S (editors). Cochrane Handbook for Systematic Reviews of Interventions Version 5.1.0 [updated March 2011]. The Cochrane Collaboration, 2011. Available from www.cochrane-handbook.org.

\section{SIGN 2011}

Scottish Intercollegiate Guidelines Network. Search Filters. http://www.sign.ac.uk/methodology/filters.html 2011.

\section{Smith 1990}

Smith AM, Malone JA. Preventing pressure ulcers in institutionalised elders: assessing the effects of small, unscheduled shifts in body position. Decubitus 1990;3(4):20-4.

\section{Sterne 2011}

Sterne JAC, Egger M, Moher D, on behalf of the Cochrane Bias Methods Group (editors). Chapter 10: Addressing reporting biases. In: Higgins JPT, Green S (editors). Cochrane Handbook for Systematic Reviews of Interventions Version 5.1.0 [updated March 2011]. The Cochrane Collaboration, 2011. Available from www.cochrane-handbook.org.

\section{The CONSORT Statement 2010}

The CONSORT Group. The CONSORT Statement . http:// www.consort-statement.org/consort-statement/ 2012.

\section{Thomas 1996}

Thomas DR, Goode PS, Tarquine PH, Allman RM. Hospitalacquired pressure ulcers and risk of death. Journal of the American Geriatrics Society 1996;44:1435-40.

\section{Thompson 2005}

Thompson D. An evaluation of the Waterlow pressure ulcer riskassessment tool. British Journal of Nursing 1995;14(8):455-9.

\section{Trinkoff 2001}

Trinkoff A, Storr C, Lipscomb J. Physically demanding work and inadequate sleep, pain, medication use and absenteeism in registered nurses. Journal of Occupational and Environmental Medicine 2001;43(4):355-63.

\section{Vanderwee 2005}

Vanderwee K, Grypdonck M, Defloor T. Effectiveness of an alternating pressure air mattress for the prevention of pressure ulcers. Age and Ageing 2005;34:261-7.

\section{Vieira 2009}

Vieira E, Kumar S. Safety analysis of patient transfers and handling tasks. Quality and Safety in Health Care 2009;18:380-4. 
CHARACTERISTICS OF STUDIES

Characteristics of included studies [ordered by study ID]

Defloor 2005

Methods

Study design: 5-armed cluster RCT with a 4-week (28-day) follow-up period (only 4 arms analysed in this review - see below).

Quote: "Each ward applied the prevention scheme selected for a period of 4 weeks. The randomisation procedure was repeated for a second period of 4 weeks. During the second period each ward used a different prevention scheme than used in the first period" (pp 39).

Ethics and informed consent: ethics approval and consent obtained.

\section{Sample size calculation: yes.}

ITT analysis: participants analysed in the groups to which they were assigned, but data were incomplete for 24 participants, and they were not included in the analysis

Quote: "The observations were incomplete in the case of 24 patients."

\section{Participants}

Location: 32 wards across 11 nursing homes in Flanders, Belgium

Baseline data reported in relation to group comparisons for age, gender and Braden scale scores

\section{Mean ages:}

Group A: 85.2 years $( \pm 7.2)$

Group B: 85.2 years $( \pm 6.2)$

Group C: 84.7 years $( \pm 7.7)$

Group D: 85.4 years $( \pm 7.3)$

Inclusion criteria: 838 people fulfilled inclusion criteria. This review excludes participants from the usual care group who received care that was different in terms of both support surface AND repositioning.

1. Geriatric residents with a Braden score of $<17$ or a Norton score of $<12$.

2. Informed consent of the patient/family.

3. No PU at time of recruitment to study.

Exclusion criteria: none stated, but total of 1114 people excluded.

Aim(s): to investigate the effect of 4 different preventative regimes involving either frequent turning (2to 3 -hourly) or the use of a pressure-reducing mattress in combination with less frequent turning (4- to 6-hourly).

Group A: 2-hourly turning regimen on standard mattress (65 randomised, 63 analysed)

Group B: 3-hourly turning regimen on standard mattress (65 randomised, 58 analysed)

Group C: 4-hourly turning regimen on viscoelastic polyurethane (pressure-relieving) mattress (67 randomised, 66 analysed).

Group D: 6-hourly turning regimen on viscoelastic polyurethane (pressure-relieving) mattress (65 randomised, 63 analysed).

Alternating turning positions: semi-Fowlers with feet elevated $30^{\circ}$ alternating with $30^{\circ}$ lateral rotation, pillow placement under back from shoulder on standard mattress 
Defloor 2005 (Continued)

Specified sitting position: experimental group sitting periods were recorded but not standardised; they sat on thick air cushions. Backrest tilt on chair, legs on footrest but heels not supported. Cushion for back.

Group 2 Control: $\mathrm{n}=576$ patients.

Care given according to patients' level of risk; water mattresses, alternating mattresses, sheepskins and gel cushions; based on nurses' clinical judgement. No PU risk assessment tool used. For the purposes of this review we have disregarded this group since their care was highly heterogeneous and differed systematically from the others in terms of BOTH the support surface provision policy AND the (absence of a) repositioning policy.

Study date(s): not stated.

Outcomes

Primary outcome: incidence of a PU (any category) during a 28-day period.

Seondary outcomes: risk assessment using Braden and Norton scores.

Time points: twice weekly for 4 weeks

Notes Not reported whether water mattresses, alternating mattresses, sheepskins and gel cushions were used singly or in combination with each other.

\section{Risk of bias}

\begin{tabular}{lll}
\hline Bias & Authors' judgement & Support for judgement \\
\hline $\begin{array}{l}\text { Random sequence genera- } \\
\text { tion (selection bias) }\end{array}$ & Low risk & $\begin{array}{l}\text { Quote:“Using computerised randomisation tables, the prevention schemes } \\
\text { were randomly allocated to } 32 \text { wards (table 1). }\end{array}$ \\
& $\begin{array}{l}\text { Randomisation also occurred over a second 4-week period. During this second } \\
\text { period, each ward used a different prevention scheme than used in the first 4- } \\
\text { week period (pp. 39). } \\
\text { Diagram of randomisation schedule included in the paper as a table pp 39. }\end{array}$
\end{tabular}

Allocation concealment Unclear risk
(selection bias)

Quote: "a sealed envelope containing all the room numbers in a random order was opened. The first 5 patients who satisfied the inclusion criteria were included."

Quote: "labour intensive nature of some of the prevention schemes, the number of patients participating in the experimental groups was limited to 5 per ward."

Comment: concern that allocation not fully concealed

\begin{tabular}{|c|c|c|}
\hline $\begin{array}{l}\text { Blinding of participants } \\
\text { and personnel (perfor- } \\
\text { mance bias) } \\
\text { All outcomes }\end{array}$ & High risk & $\begin{array}{l}\text { Quote: "'It was impossible to blind the nurses for preventative care." } \\
\text { Comment: Not blinded }\end{array}$ \\
\hline $\begin{array}{l}\text { Blinding of outcome as- } \\
\text { sessment (detection bias) } \\
\text { All outcomes }\end{array}$ & High risk & $\begin{array}{l}\text { Quote: "The nurses were blinded for the Braden and Norton scores of their in- } \\
\text { dividual patients." } \\
\text { Comment: impossible for nursing staff to be blinded due to the differences in } \\
\text { the types and varieties of turning regimens }\end{array}$ \\
\hline $\begin{array}{l}\text { Incomplete outcome data } \\
\text { (attrition bias) } \\
\text { All outcomes }\end{array}$ & High risk & $\begin{array}{l}\text { Flow chart (fig 1, pp 41) showed patient attrition across each of the } 5 \text { groups } \\
\text { Quotes: }\end{array}$ \\
\hline
\end{tabular}



od."

"The data on three patients were incomplete and it could not be guaranteed that the protocol was strictly followed. Those patients were excluded."

Comment: ITT analysis not implemented

\begin{tabular}{lll}
\hline $\begin{array}{l}\text { Selective reporting (re- } \\
\text { porting bias) }\end{array}$ & Unclear risk & $\begin{array}{l}\text { Comment: clinical outcomes were presented in Tables 2 and } 3 \text { of the paper. A } \\
\text { published protocol was not available. Measures used reflect aims of the inter- } \\
\text { vention and outcomes }\end{array}$ \\
\hline Other bias & Low risk & None identified. \\
\hline
\end{tabular}

\section{Moore 2011}

Methods Study design: 2-armed cluster RCT with a 4-week (28-day) follow-up period.

Ethics and informed consent: ethics approval and consent obtained.

\section{Sample size calculation: yes.}

ITT analysis: yes, all participants randomised were analysed.

\section{Participants}

Location: 12 hospital sites with long-term residents in Ireland.

Mean age: not reported

Baseline data reported in relation to group comparisons for age, gender and Braden scale scores.

\section{Inclusion criteria:}

1. In-patient in a long term geriatric facility.

2. Over 65 years of age.

3. At risk of PU development using the activity and mobility components of Braden scale.

4. No PU at time of recruitment to study.

5. No medical condition that would preclude the use of repositioning.

6. Consent.

Exclusion criteria: patients with existing PU. Total of 57 patients excluded.

$\operatorname{Aim}(\mathbf{s})$ : to examine whether repositioning using $30^{\circ}$ tilt and 3 -h repositioning reduces the incidence of PU compared with usual care.

Group 1: $30^{\circ}$ tilt ( $n=99$ participants randomised, 99 analysed)

Repositioning by clinical staff using $30^{\circ}$ tilt at night (left side, back, right side, back) 3-h overnight ( 8 pm-8 am). During the day, position changes occurred 2-3h.

Group 2: Usual care ( $\mathrm{n}=114$ participants randomised, 99 analysed)

Usual care consisted of repositioning by clinical staff every 6 -h using the $90^{\circ}$ tilt (left side, back, right side, back) overnight, ( $8 \mathrm{pm}-8 \mathrm{am}$ ). During the day, position changes occurred 2- to 3-h. 
Co-interventions : participants in both groups nursed as per planned care regarding nutritional regimens, toileting, changing of incontinence pads, preparation for feeding, and pressure redistribution devices on chairs. Repositioned every 2 - to 3 -h during the day.

Outcomes

Primary outcome: incidence of all PUs during a 28-day period

Quote: "The EPUAP pressure ulcer (PU) classification system, ranging from non-blanching erythema of intact skin to full scale tissue destruction" (Grades I to IV)

Quote: "A pressure ulcer was defined as localised areas of tissue damage caused to skin and underlying soft tissue caused by sustained mechanical loading and shearing forces."

\section{Secondary outcomes:}

- Risk assessment using Braden scale components to predict PU development:

- Activity scores

- Mobility

- Economic outcomes: 1) mean daily nurse time for repositioning, 2) nurse time cost per patient, 3) cost of patient free of PU; and, 4) projected annual cost

Validity of measures: inter-rater reliability not reported, but quote: "The skin was then assessed by the assigned key staff member, the clinical manager, and the researcher. Agreement between assessors was reached by comparing patients' skin condition to images of the EPUAP grading system."

Time points: weekly follow-up over 4 weeks.

Notes

PU risk status on study entry not stated by group.

Imbalances in cluster size.

ICC used in analysis and reported in text, Kish design effect reported (pp 2639).

\section{Risk of bias}

Bias Authors' judgement Support for judgement

Random sequence genera- Low risk tion (selection bias)

Quote: "The clusters were the specific study sites $(n=12)$ and these were randomly allocated to either the intervention group or the control group."

Quote: "The allocation was generated by a statistician not directly involved with the study and was determined using computerised randomisation."

Allocation concealment Low risk (selection bias)
Quote: "The allocation was generated by a statistician not directly involved with the study and was determined using computerised randomisation."

Quote: “... allocation concealment was achieved through use of distance randomisation, meaning that the statistician, not the researcher, controlled the randomisation sequence."

Quote: 'The research design employed was ... open label, pragmatic" (pp 2635)

Comment: Impossible for participants and nurses to be blinded.

Blinding of participants High risk
and personnel (perfor-
mance bias)
All outcomes

Blinding of outcome as- High risk sessment (detection bias) All outcomes 
Comment: not stated, but most likely impossible. In an effort to minimise this form of bias, several assessors were used, although inter-rater reliability data were not presented.

\begin{tabular}{ll}
\hline $\begin{array}{l}\text { Incomplete outcome data } \\
\text { (attrition bias) }\end{array}$ & Low risk \\
All outcomes & (ITT) basis." \\
& Flow chart (fig 3, pp 2639) showed patient attrition across the 2 groups, but \\
& same number of patients who were randomised were also analysed.
\end{tabular}

Selective reporting (re- Low risk
porting bias)

Comment: clinical outcome, development of PU was reported. A published protocol was not available. Measures used reflect aims of the intervention and outcome.

Other bias Unclear risk

1. No table/data to show baseline comparisons for each group and whether PU risk was equivalent at study entry.

2. Economic data: The rationale for changing between outcome measures of "patient free of ulcer" and "pressure ulcer avoided" is unclear. In this instance these outcome measures would appear to be equivalent since the number of patients developing an ulcer and the number of PU developing during the trial was the same $(n=16)$.

Ethics and informed consent: ethics approval and consent obtained

\section{Sample size calculation: yes}

ITT analysis: reported as ITT

Location: medical ward of an acute general hospital in
Mean age:
Group 1: 70.1 years $( \pm 11.1)$
Group 2: 70.5 years $( \pm 14.7)$
Baseline data reported in relation to group comparisons
scale scores
Inclusion criteria:
1. Elderly patients
2. At risk of developing a pressure ulcer using Waterlow
3. Able to lie in $30^{\circ}$ tilt position
4. Given informed consent
5. No existing pressure damage
6. Caucasian

Exclusion criteria: not stated 
Group 1 Intervention: $\mathrm{n}=23$ patients randomised, 18 analysed

Repositioning using $30^{\circ}$ tilt (left side, back, right side, back) 2-3-hourly overnight, 2-3-hourly during the day.

Sacrum and heels free from contact with support surface

Support mattress: alternating pressure mattress or low air loss mattress.

Group 2 Control: $\mathrm{n}=23$ patients randomised, 21 analysed.

$90^{\circ}$ lateral and supine positions 2-3-hourly overnight, 2-3-hourly during the day.

Support mattress: low air loss mattress.

Study date(s): April-July 1999

Outcomes Primary outcome: incidence of non-blanchable erythema during a 24-h period

Quote: "NBE was used as a definition for pressure damage."

Validity of measures: not reported

Time points: one

Notes

\section{Risk of bias}

\begin{tabular}{lll}
\hline Bias & Authors' judgement & Support for judgement \\
\hline $\begin{array}{l}\text { Random sequence genera- } \\
\text { tion (selection bias) }\end{array}$ & Unclear risk & $\begin{array}{l}\text { Quote:“The randomisation was based on block allocation" } \\
\text { Comment: No mention of how the blocks were generated (i.e., computer or } \\
\text { random number table) or allocation ratio to each block. Thus the process for } \\
\text { electing the blocks is unclear. }\end{array}$
\end{tabular}

\begin{tabular}{|c|c|c|}
\hline \multirow[t]{4}{*}{$\begin{array}{l}\text { Allocation concealment } \\
\text { (selection bias) }\end{array}$} & Unclear risk & $\begin{array}{l}\text { Quote: "specific intervention being selected by sequential opening of sealed } \\
\text { opaque envelopes." }\end{array}$ \\
\hline & & $\begin{array}{l}\text { Quote: "The ward staff were then handed the sequentially numbered en- } \\
\text { velopes containing randomisation code and the researcher left the clinical } \\
\text { area." }\end{array}$ \\
\hline & & $\begin{array}{l}\text { Comment: This trial used blocked randomization with group assignments be- } \\
\text { ing revealed after recruitment, therefore there is the potential to be able to } \\
\text { predict future assignments. }\end{array}$ \\
\hline & & $\begin{array}{l}\text { Potential for interference with envelopes, which are more susceptible to ma- } \\
\text { nipulation than are other approaches. . }\end{array}$ \\
\hline $\begin{array}{l}\text { Blinding of participants } \\
\text { and personnel (perfor- } \\
\text { mance bias) } \\
\text { All outcomes }\end{array}$ & High risk & $\begin{array}{l}\text { Comment: not stated. Impossible for nursing staff to be blinded due the differ- } \\
\text { ences in the intervention and usual care. Difficult to conceal from participants } \\
\text { and nursing staff once patients were randomised. }\end{array}$ \\
\hline \multirow[t]{2}{*}{$\begin{array}{l}\text { Blinding of outcome as- } \\
\text { sessment (detection bias) } \\
\text { All outcomes }\end{array}$} & Low risk & $\begin{array}{l}\text { Quote: "The next morning the researcher was unaware of which method of } \\
\text { repositioning had been used, therefore masking the researcher to treatment } \\
\text { allocation." }\end{array}$ \\
\hline & & Comment: researcher blinded totreatment group \\
\hline
\end{tabular}


Young 2004 (Continued)

Incomplete outcome data High risk (attrition bias)

All outcomes
Quote: "A total of 7 patients had no post intervention data collected."

Quote: "Statistical comparisons were made on an intention-to-treat basis."

"No post-intervention assessment of pressure damage was performed on any of these seven subjects."

Comment: use of ITT stated, however, participants were excluded from the analysis if they discontinued the intervention or were nursed on a foam mattress (pp 92).

Selective reporting (re- Low risk
porting bias)
porting bias)
Comment: clinical outcome, development of PU was reported. A published protocol was not available. Measures used reflect aims of the intervention and outcome.

Other bias Low risk Comments: None identified.

\author{
Abbreviations \\ $\mathrm{COI}=$ conflict of interest \\ fig = figure \\ $\mathrm{h}=\operatorname{hour}(\mathrm{s})$ \\ ICC = intra-cluster correlation coefficient \\ ITT = intention to treat analysis \\ $\mathrm{NBE}=$ non-blanchable erythema \\ $\mathrm{pp}=$ page $(\mathrm{s})$ \\ $\mathrm{PU}=$ pressure ulcer
}

Characteristics of excluded studies [ordered by study ID]

\begin{tabular}{ll}
\hline Study & Reason for exclusion \\
\hline Vanderwee 2007 & $\begin{array}{l}\text { Inclusion/Exclusion criteria: patients who had a pre-existing grade } 1 \text { PU (i.e. non-blanchable ery- } \\
\text { thema) were included, and those who did not have non-blanchable erythema }(\mathrm{n}=1944) \text { were ex- } \\
\text { cluded (fig 1, pp 63) }\end{array}$ \\
\hline
\end{tabular}

\title{
Abbreviations
}

fig = figure

$\mathrm{PU}=$ pressure ulcer

Characteristics of ongoing studies [ordered by study ID]

\section{Bergstrom}

\begin{tabular}{ll}
\hline Trial name or title & TURN Study \\
\hline Methods & Cluster RCT \\
\hline Participants & 66 nursing short stay $(<7$ days) and long stay ( 90 days) aged care residents 65 years and over \\
\hline Interventions & In-bed repositioning every $2 \mathrm{~h}$ compared to $3 \mathrm{~h}$ or $4 \mathrm{~h}$ and associated continence care \\
\hline Outcomes & Incidence of PU \\
\hline Starting date & Started in 2008 and completed in June 2011 \\
\hline Contact information & Nancy Bergstrom
\end{tabular}


Bergstrom (Continued)

Theodore J and Mary E Trumble Professor of Aging Research

Associate Dean for Research (Interim)

School of Nursing

University of Texas Health Science Center-Houston

6901 Bertner Ave, 6.625

Houston 77030

Email: Nancy.Bergstrom@uth.tmc.edu

Notes

Correspondence with N Bergstrom. Study has been submitted for publication and is under review at the time of writing this review

\section{DATA AND ANALYSES}

Comparison 1. $2 \mathrm{~h}$ versus $3 \mathrm{~h}$ repositioning on standard hospital mattresses

\begin{tabular}{llllll}
\hline Outcome or subgroup title & $\begin{array}{l}\text { No. of } \\
\text { studies }\end{array}$ & $\begin{array}{l}\text { No. of } \\
\text { partici- } \\
\text { pants }\end{array}$ & Statistical method & Effect size \\
\hline 1 Pressure ulcer risk (category 1 to 4) & 1 & 121 & Risk Ratio (M-H, Fixed, 95\% Cl) & $0.90[0.69,1.16]$ \\
\hline 2 Pressure ulcer risk (category 2 to 4) & 1 & 121 & Risk Ratio (M-H, Fixed, 95\% Cl) & $0.59[0.28,1.26]$ \\
\hline
\end{tabular}

Analysis 1.1. Comparison $12 \mathrm{~h}$ versus $3 \mathrm{~h}$ repositioning on standard hospital mattresses, Outcome 1 Pressure ulcer risk (category 1 to 4).

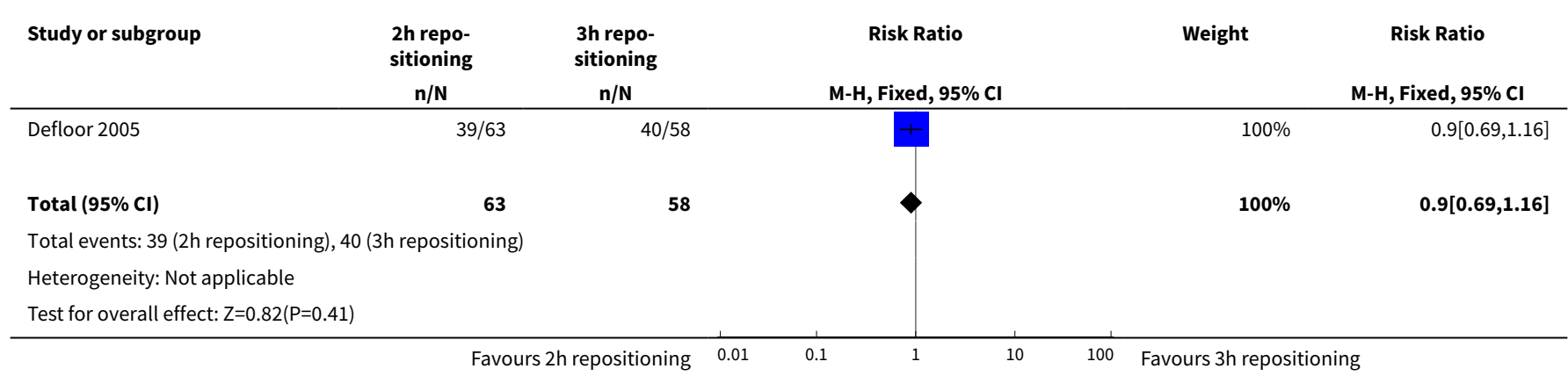

Analysis 1.2. Comparison $12 \mathrm{~h}$ versus $3 \mathrm{~h}$ repositioning on standard hospital mattresses, Outcome 2 Pressure ulcer risk (category 2 to 4).

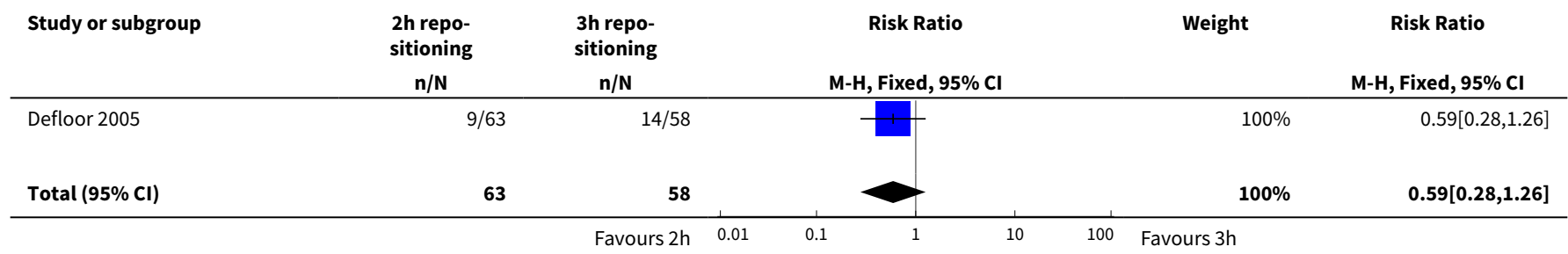




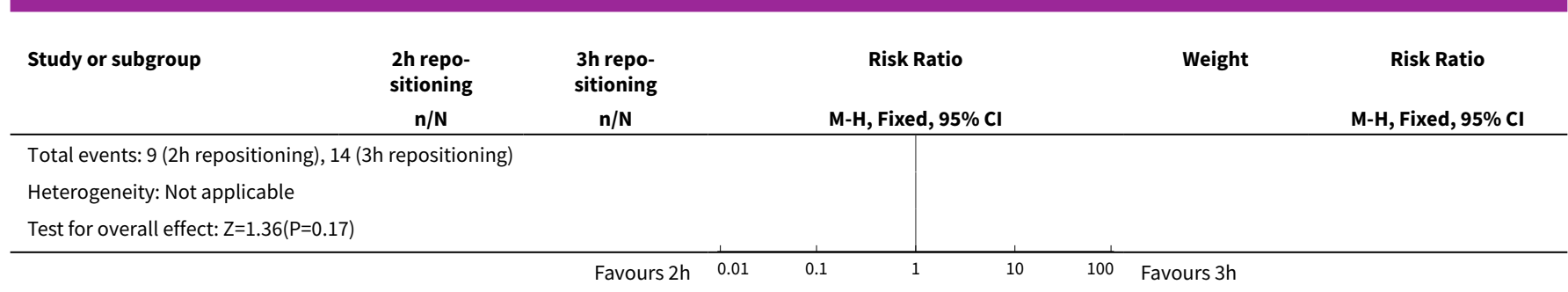

Comparison 2. $4 \mathrm{~h}$ versus $6 \mathrm{~h}$ repositioning on viscoelastic foam mattresses

\begin{tabular}{lllll}
\hline Outcome or subgroup title & $\begin{array}{l}\text { No. of } \\
\text { studies }\end{array}$ & $\begin{array}{l}\text { No. of } \\
\text { partici- } \\
\text { pants }\end{array}$ & Statistical method & Effect size \\
\hline 1 Pressure ulcer risk (category 1 to 4) & 1 & 129 & Risk Ratio (M-H, Fixed, 95\% Cl) & $0.73[0.53,1.02]$ \\
\hline 2 Pressure ulcer risk (category 2 to 4) & 1 & 129 & Risk Ratio (M-H, Fixed, 95\% Cl) & $0.19[0.04,0.84]$ \\
\hline
\end{tabular}

Analysis 2.1. Comparison $24 \mathrm{~h}$ versus $6 \mathrm{~h}$ repositioning on viscoelastic foam mattresses, Outcome 1 Pressure ulcer risk (category 1 to 4).

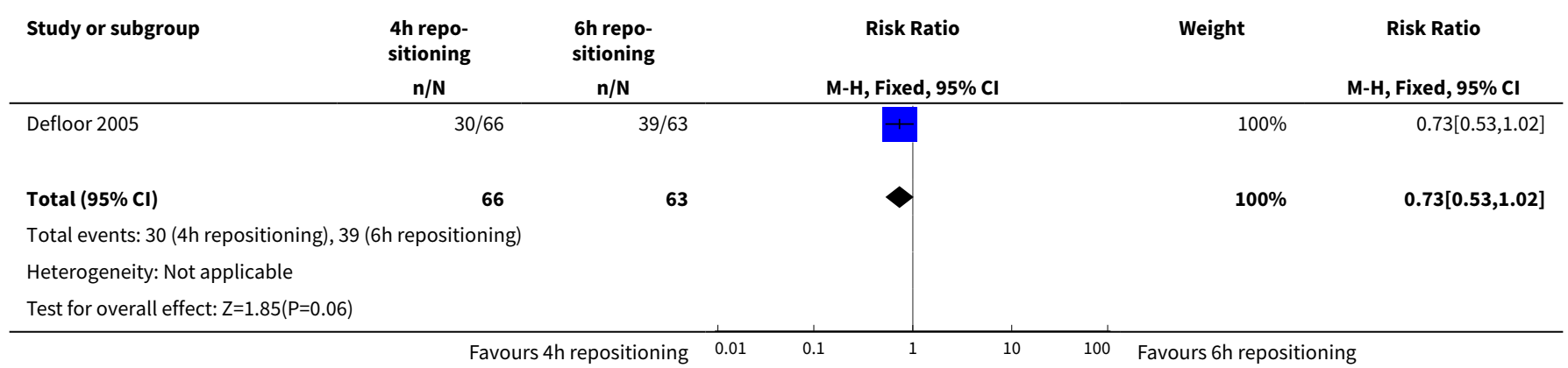

Analysis 2.2. Comparison $24 \mathrm{~h}$ versus $6 \mathrm{~h}$ repositioning on viscoelastic foam mattresses, Outcome 2 Pressure ulcer risk (category 2 to 4).

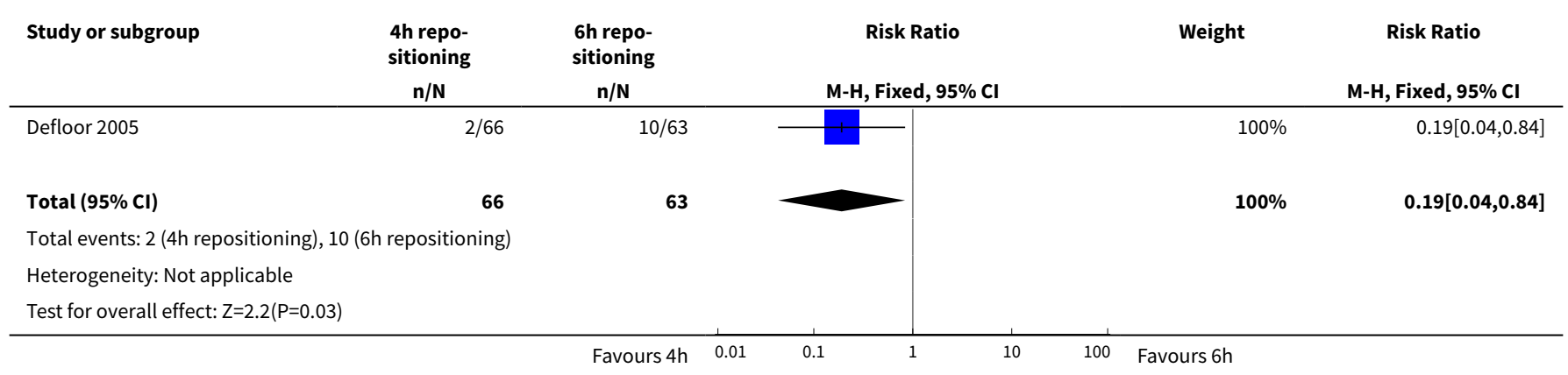


Comparison 3. $30^{\circ}$ tilt 3-hourly overnight versus $90^{\circ}$ tilt overnight

\begin{tabular}{lllll}
\hline Outcome or subgroup title & $\begin{array}{l}\text { No. of } \\
\text { studies }\end{array}$ & $\begin{array}{l}\text { No. of par- } \\
\text { ticipants }\end{array}$ & Statistical method & Effect size \\
\hline 1 Pressure ulcer risk (category 1 to 4) & 2 & 252 & Risk Ratio (M-H, Random, 95\% Cl) & $0.62[0.10,3.97]$ \\
\hline
\end{tabular}

Analysis 3.1. Comparison $330^{\circ}$ tilt 3-hourly overnight versus $90^{\circ}$ tilt overnight, Outcome 1 Pressure ulcer risk (category 1 to 4).

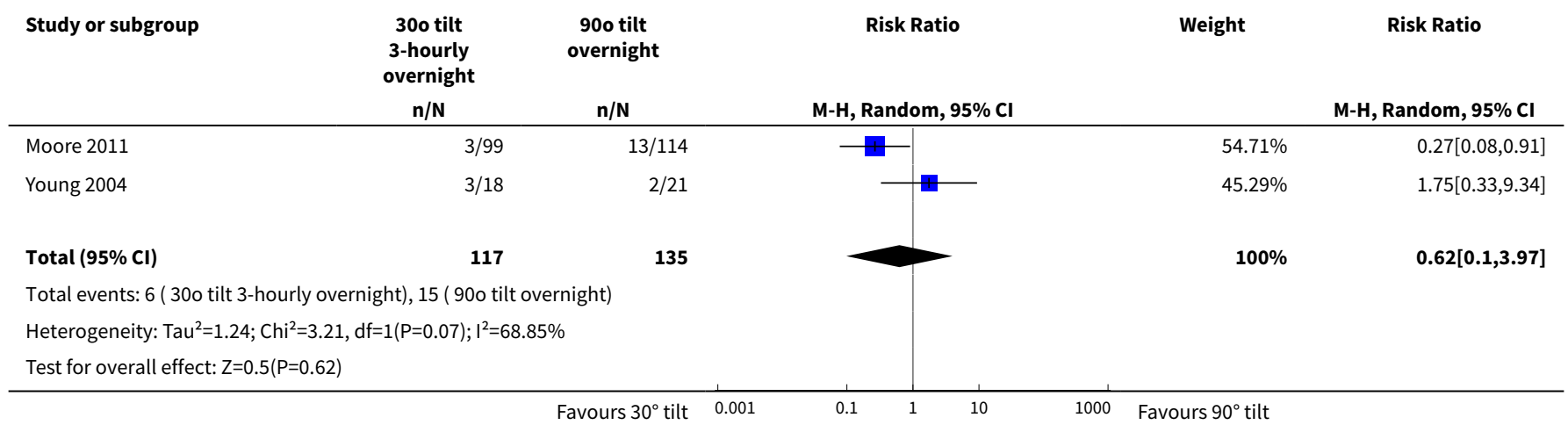

\section{APPENDICES}

\section{Appendix 1. Ovid MEDLINE, Ovid EMBASE and EBSCO CINAHL effectiveness search strategies}

\section{Ovid MEDLINE}

1 exp Pressure Ulcer/ (5231)

2 (pressure adj (ulcer ${ }^{\star}$ or sore $\left.e^{\star}\right)$ ).tw. (4365)

3 (decubitus adj (ulcer ${ }^{\star}$ or sore $\left.\left.{ }^{\star}\right)\right)$. tw. (579)

4 (bedsore $^{\star}$ or (bed adj sore $\left.{ }^{\star}\right)$ ).tw. (245)

5 or/1-4 (6546)

6 exp Posture/ (27564)

7 (reposition* or re-position*).tw. (6619)

8 position*.tw. (235791)

9 (turn* adj5 patient $^{\star}$ ).tw. (3591)

10 (turn $^{\star}$ adj5 interval ${ }^{\star}$ ).tw. (126)

11 (turn* adj5 frequen $^{\star}$ ).tw. (777)

12 turning.tw. (7625)

13 (body adj5 posture*).tw. (1092)

14 pressure relie ${ }^{\star}$.tw. (417)

15 (mobilis* or mobiliz ${ }^{\star}$ ).tw. (34978)

16 or/6-15 (301537)

175 and 16 (834)

18 randomized controlled trial.pt. (240548)

19 controlled clinical trial.pt. (39492)

20 randomized.ab. (195665)

21 placebo.ab. (91366)

22 clinical trials as topic.sh. (79465)

23 randomly.ab. (134439)

24 trial.ti. (72586)

25 or/18-24 (543387) 
26 (animals not (humans and animals)).sh. (1612439)

2725 not 26 (494803)

2817 and 27 (107)

\section{Ovid EMBASE}

1 exp Decubitus/ (9094)

2 (pressure adj (ulcer\$ or sore\$)).tw. (5623)

3 (decubitus adj (ulcer\$ or sore\$)).tw. (773)

4 (bedsore or (bed adj sore\$)).tw. (415)

5 or/1-4 (10271)

6 exp patient positioning/ (10577)

7 (reposition\$ or re-position\$).tw. (9126)

8 position\$.tw. (316430)

9 (turn\$ adj5 patient\$).tw. (5673)

10 (turn\$ adj5 interval\$).tw. (168)

11 (turn\$ adj5 frequen\$).tw. (1215)

12 turning.tw. (10505)

13 (body adj5 posture\$).tw. (1519)

14 or/6-13 (344598)

155 and 14 (1057)

16 Randomized controlled trials/ (24734)

17 Single-Blind Method/ (15386)

18 Double-Blind Method/ (85329)

19 Crossover Procedure/ (31526)

20 (random \$ or factorial\$ or crossover\$ or cross over\$ or cross-over\$ or placebo $\$$ or assign\$ or allocat\$ or volunteer\$).ti,ab. (930632)

21 (doubl\$ adj blind\$).ti,ab. (89452)

22 (singl\$ adj blind\$).ti,ab. (9568)

23 or/16-22 (964333)

24 animal/ (717007)

25 human/ (8542238)

2624 not 25 (478486)

2723 not 26 (932575)

2815 and 27 (175)

\section{EBSCO CINAHL}

S16 S5 and S15

$\mathrm{S} 15 \mathrm{~S} 6$ or $\mathrm{S} 7$ or $\mathrm{S} 8$ or $\mathrm{S} 9$ or $\mathrm{S} 10$ or $\mathrm{S} 11$ or $\mathrm{S} 12$ or $\mathrm{S} 13$ or $\mathrm{S} 14$

S14 TI body N5 posture* or AB body N5 posture*

S13 TI turning or $A B$ turning

S12 TI turn* N5 frequen* or AB turn* N5 frequen *

S11 TI turn* N5 interval* or AB turn* N5 interval ${ }^{*}$

S10 TI turn* N5 patient* or AB turn* N5 patient*

S9 TI position* or AB position*

S8 TI ( reposition* or re-position ${ }^{\star}$ ) or $\mathrm{AB}$ ( reposition ${ }^{\star}$ or re-position ${ }^{\star}$ )

S7 (MH "Patient Positioning+")

S6 (MH "Posture+")

$\mathrm{S} 5 \mathrm{~S} 1$ or $\mathrm{S} 2$ or S3 or S4

S4 TI ( bedsore or bed sore) or AB ( bedsore or bed sore )

S3 TI ( pressure ulcer ${ }^{\star}$ or pressure sore ${ }^{\star}$ ) or $A B$ ( pressure ulcer ${ }^{\star}$ or pressure sore ${ }^{\star}$ )

S2 TI decubitus or AB decubitus

S1 (MH "Pressure Ulcer")

\section{Appendix 2. Ovid MEDLINE economics search strategy}

1 exp Pressure Ulcer/

2 (pressure adj (ulcer ${ }^{\star}$ or sore $\left.\left.{ }^{\star}\right)\right)$.tw.

3 (decubitus adj (ulcer ${ }^{\star}$ or sore $\left.)^{\star}\right)$ ).tw.

4 (bedsore $^{\star}$ or (bed adj sore $\left.\left.{ }^{\star}\right)\right)$.tw.

5 or/1-4

6 exp Posture/

7 (reposition* or re-position*).tw. 
8 position*.tw.

9 (turn $^{\star}$ adj5 patient $\left.{ }^{\star}\right)$.tw.

10 (turn $^{\star}$ adj5 interval $\left.{ }^{\star}\right)$.tw.

11 (turn $^{\star}$ adj5 frequen $\left.{ }^{\star}\right)$.tw.

12 turning.tw.

13 (body adj5 posture ${ }^{\star}$ ).tw.

14 pressure relie*.tw.

15 (mobilis* or mobiliz*).tw.

16 or/6-15

175 and 16

18 economics/

19 exp "costs and cost analysis"/

20 economics, dental/

21 exp "economics, hospital"/

22 economics, medical/

23 economics, nursing/

24 economics, pharmaceutical/

25 (economic ${ }^{\star}$ or cost or costs or costly or costing or price or prices or pricing or pharmacoeconomic ${ }^{\star}$ ).ti,ab.

26 (expenditure* not energy).ti,ab.

27 value for money.ti,ab.

28 budget $^{*}$.ti,ab.

29 or/18-28

30 ((energy or oxygen) adj cost).ti,ab.

31 (metabolic adj cost).ti,ab.

32 ((energy or oxygen) adj expenditure).ti,ab.

33 or/30-32

3429 not 33

35 letter.pt.

36 editorial.pt.

37 historical article.pt.

38 or/35-37

3934 not 38

40 Animals/

41 Humans/

$4240 \operatorname{not}$ ( 40 and 41 )

4339 not 42

4417 and 43

\section{Appendix 3. Risk of bias criteria}

\section{Was the allocation sequence adequately generated?}

\section{Low risk of bias}

The investigators describe a random component in the sequence generation process such as: referring to a random number table; using a computer random number generator; coin tossing; shuffling cards or envelopes; throwing dice; drawing of lots.

\section{High risk of bias}

The investigators describe a non-random component in the sequence generation process. Usually, the description would involve some systematic, non-random approach, for example: sequence generated by odd or even date of birth; sequence generated by some rule based on date (or day) of admission; sequence generated by some rule based on hospital or clinic record number.

\section{Unclear}

Insufficient information about the sequence generation process to permit judgment of low or high risk of bias.

\section{Was the treatment allocation adequately concealed?}

\section{Low risk of bias}

Participants and investigators enrolling participants could not foresee assignment because one of the following, or an equivalent method, was used to conceal allocation: central allocation (including telephone, web-based and pharmacy-controlled randomisation); sequentially-numbered drug containers of identical appearance; sequentially-numbered, opaque, sealed envelopes. 


\section{High risk of bias}

Participants or investigators enrolling participants could possibly foresee assignments and thus introduce selection bias, such as allocation based on: using an open random allocation schedule (e.g. a list of random numbers); assignment envelopes were used without appropriate safeguards (e.g. if envelopes were unsealed or non-opaque or not sequentially numbered); alternation or rotation; date of birth; case record number; any other explicitly unconcealed procedure.

\section{Unclear}

Insufficient information to permit judgment of low or high risk of bias. This is usually the case if the method of concealment is not described or not described in sufficient detail to allow a definite judgment, for example if the use of assignment envelopes is described, but it remains unclear whether envelopes were sequentially numbered, opaque and sealed.

\section{Blinding - was knowledge of the allocated interventions adequately prevented during the study?}

\section{Low risk of bias}

Any one of the following.

- No blinding, but the review authors judge that the outcome and the outcome measurement were not likely to be influenced by lack of blinding.

- Blinding of participants and key study personnel ensured, and unlikely that the blinding could have been broken.

- Either participants or some key study personnel were not blinded, but outcome assessment was blinded and the non-blinding of others unlikely to introduce bias.

\section{High risk of bias}

Any one of the following.

- No blinding or incomplete blinding, and the outcome or outcome measurement is likely to be influenced by lack of blinding.

- Blinding of key study participants and personnel attempted, but likely that the blinding could have been broken.

- Either participants or some key study personnel were not blinded, and the non-blinding of others likely to introduce bias.

\section{Unclear}

Either of the following.

- Insufficient information to permit judgement of low or high risk of bias.

- The study did not address this outcome.

\section{Were incomplete outcome data adequately addressed?}

\section{Low risk of bias}

Any one of the following.

- No missing outcome data.

- Reasons for missing outcome data unlikely to be related to true outcome (for survival data, censoring unlikely to be introducing bias).

- Missing outcome data balanced in numbers across intervention groups, with similar reasons for missing data across groups.

- For dichotomous outcome data, the proportion of missing outcomes compared with observed event risk not enough to have a clinically relevant impact on the intervention effect estimate.

- For continuous outcome data, plausible effect size (difference in means or standardised difference in means) among missing outcomes not enough to have a clinically relevant impact on observed effect size.

- Missing data have been imputed using appropriate methods.

\section{High risk of bias}

Any one of the following.

- Reason for missing outcome data likely to be related to true outcome, with either imbalance in numbers or reasons for missing data across intervention groups.

- For dichotomous outcome data, the proportion of missing outcomes compared with observed event risk enough to induce clinically relevant bias in intervention effect estimate.

- For continuous outcome data, plausible effect size (difference in means or standardised difference in means) among missing outcomes enough to induce clinically relevant bias in observed effect size.

- 'As-treated' analysis done with substantial departure of the intervention received from that assigned at randomisation. 
- Potentially inappropriate application of simple imputation.

\section{Unclear}

Either of the following.

- Insufficient reporting of attrition/exclusions to permit judgement of low or high risk of bias (e.g. number randomised not stated, no reasons for missing data provided).

- The study did not address this outcome.

\section{Are reports of the study free of suggestion of selective outcome reporting?}

\section{Low risk of bias}

Either of the following.

- The study protocol is available and all of the study's pre-specified (primary and secondary) outcomes that are of interest in the review have been reported in the pre-specified way.

- The study protocol is not available, but it is clear that the published reports include all expected outcomes, including those that were pre-specified (convincing text of this nature may be uncommon).

\section{High risk of bias}

Any one of the following.

- Not all of the study's pre-specified primary outcomes have been reported.

- One or more primary outcomes are reported using measurements, analysis methods or subsets of the data (e.g. subscales) that were not pre-specified.

- One or more reported primary outcomes were not pre-specified (unless clear justification for their reporting is provided, such as an unexpected adverse effect).

- One or more outcomes of interest in the review are reported incompletely so that they cannot be entered in a meta-analysis.

- The study report fails to include results for a key outcome that would be expected to have been reported for such a study.

\section{Unclear}

Insufficient information to permit judgment of low or high risk of bias. It is likely that the majority of studies will fall into this category.

\section{Other sources of potential bias}

\section{Low risk of bias}

The study appears to be free of other sources of bias.

\section{High risk of bias}

There is at least one important risk of bias. For example, the study:

- had a potential source of bias related to the specific study design used; or

- has been claimed to have been fraudulent; or

- had some other problem.

\section{Unclear}

There may be a risk of bias, but there is either:

- insufficient information to assess whether an important risk of bias exists; or

- insufficient rationale or evidence that an identified problem will introduce bias.

WHAT'S NEW

\begin{tabular}{lll}
\hline Date & Event & Description \\
\hline 24 February 2015 & Amended & Contact details updated. \\
\hline
\end{tabular}




\section{CONTRIBUTIONS OF AUTHORS}

Wendy Chaboyer: conceived and designed the review, checked the quality of data extraction, analysed or interpreted data, performed part of data analysis or interpretation, performed part of the writing or editing, made an intellectual contribution to, secured funding for and approved the final version of the review prior to submission.

Brigid Gillespie: conceived, designed and co-ordinated the review. Extracted data, undertook quality assessment, analysed or interpreted data, performed part of data analysis or interpretation, performed statistical analysis and completed the first draft of the review. Performed part of writing or editing, made an intellectual contribution to and approved final review prior to submission. Wrote to study authors, experts, and companies and acted as guarantor of the review.

Elizabeth McInnes: designed the review, extracted data, undertook quality assessment, analysed or interpreted data, performed part of data analysis or interpretation, performed part of writing or editing and made an intellectual contribution to the review. Wrote to study authors, experts, and companies, performed previous work that was the foundation of the current review and approved the final review prior to submission.

Bridie Kent: analysed or interpreted data, performed part of data analysis or interpretation, performed part of writing or editing, made an intellectual contribution and approved the final review prior to submission.

Jenny Whitty: analysed or interpreted data, performed part of data analysis or interpretation, performed part of writing or editing, made an intellectual contribution, performed economic analysis and approved the final review prior to submission.

Lukman Thalib: analysed or interpreted data, performed part of data analysis or interpretation, performed part of writing or editing, made an intellectual contribution and approved the final review prior to submission.

\section{Contributions of editorial base}

Nicky Cullum: advised on methodology, interpretation and protocol content, edited and re-wrote sections of the final review including reentering and analysing data, approved the final review prior to publication.

Sally Bell-Syer: co-ordinated the editorial process, advised on methodology, interpretation and content, edited the protocol. Jo Dumville: checked the re-analysis of the data and checked the final version for publication after NC.

Ruth Foxlee: designed the search strategy and edited the search methods section.

\section{DECLARATIONS OF INTEREST}

Dr Brigid Gillespie; Dr Wendy Chaboyer; Dr Elizabeth McInnes; Dr Bridie Kent; Dr Jennifer Whitty and Dr Lukman Thalib have no conflicts of interest to declare.

\section{SOURCES OF SUPPORT}

\section{Internal sources}

- NHMRC, Australia.

The NHMRC provided funding for this review from its Centre of Research Excellence Scheme, which funds one or more of the authors

- Jennifer Whitty received a Research Fellowship funded by the Queensland Government Department of Employment, Economic Development and Innovation, Queensland Health and Griffith University, Australia.

\section{External sources}

- The National Institute from Health Research (NIHR) is the sole funder of the Cochrane Wounds Group, UK.

\section{DIFFERENCES BETWEEN PROTOCOLANDREVIEW}

We had originally planned to undertake subgroup analyses based on type of setting (long-term and acute care) and the type of patient. Although one study was conducted in an acute care setting, the others were set in long-term care facilities, and all with geriatric patients. We have instead, undertaken a subgroup analysis with regard to tilt regimes (i.e. $30^{\circ}$ versus 900 tilt) in relation to participants who developed a grade 1 pressure ulcer.

\section{N DEX TERMS}

\section{Medical Subject Headings (MeSH)}

Beds; Cost-Benefit Analysis; Patient Positioning [economics] [ ${ }^{\star}$ methods]; Pressure Ulcer [ ${ }^{\star}$ prevention \& control]; Randomized Controlled Trials as Topic; Time Factors

\section{MeSH check words}

Adult; Aged; Humans; Middle Aged 